\title{
Evidence That Guanosine Triphosphate (GTP)-Binding Proteins Control a Synaptic Response in Brain: Effect of Pertussis Toxin and GTP $\gamma$ S on the Late Inhibitory Postsynaptic Potential of Hippocampal CA3 Neurons
}

\author{
Robert H. Thalmann \\ Departments of Cell Biology, Physiology and Biophysics, and The Program in Neuroscience, Baylor College of Medicine, \\ Houston, Texas 77030
}

These experiments show that a synaptic response in brain, namely, the late inhibitory postsynaptic potential (IPSP) of hippocampal CA3 neurons in the rat hippocampal slice, was blocked by 2 compounds affecting guanosine triphosphate (GTP)-binding proteins. The first of these compounds, pertussis toxin, an inactivator of several GTP-binding proteins (G-proteins), excluding the GTP-binding protein that stimulates adenylyl cyclase, was injected intrahippocampally. The second compound, GTPrS, a nonhydrolyzable analog of GTP, was injected directly into postsynaptic neurons via the recording electrode. An ADP-ribosylation assay verified that the pertussis toxin had modified a major portion of the hippocampal pertussis toxin substrates of approximately 40,000 apparent molecular weight. Each agent blocked the conductance associated with both the late IPSP and the response to baclofen, an agonist for a putative receptor mediating the late IPSP (GABA $)_{8}$. These compounds did not block the mossy fiber excitatory postsynaptic potential

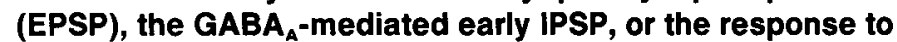
the GABA agonist 4,5,6,7-tetrahydroisoxazolo-(5,4-C)-pyridin-3-ol. It is possible that these measurements underestimated the degree of blockade of the specific potassium conductance of the late IPSP since at least a portion of the GTP $\gamma$ S-insensitive response was not a potassium conductance at all. Rather, it was a response with a reversal potential some $\mathbf{3 0 ~ m V}$ positive to that of the late IPSP.

On the basis of these experiments, I propose that the transmitter receptor of the late IPSP activates a potassium conductance via a G-protein that is sensitive to blockade by pertussis toxin and that GTP $\gamma S$ and baclofen activate a conductance that depends upon the same G-proteins and/or potassium channels as does the late IPSP.

Orthodromic synaptic stimulation of hippocampal and other forebrain neurons is followed by an early inhibitory postsynaptic potential (IPSP) that is associated with a chloride conductance

\footnotetext{
Received Jan. 15, 1988; revised May 4, 1988; accepted May 6, 1988.

Supported by NS21713. ADP-ribosylation assays were performed by D. Grenet in the laboratory of Dr. Lutz Birnbaumer. I would like to thank Drs. Lutz Birnbaumer and John J. Hablitz for useful comments on earlier versions of the manuscript.

Correspondence should be addressed to Robert $H$. Thalmann at the above address.
}

Copyright (C) 1988 Society for Neuroscience $0270-6474 / 88 / 124589-14 \$ 02.00 / 0$ and then by a late IPSP that is associated with a potassium conductance (Nicoll and Alger, 1981; Thalmann and Ayala, 1982; Alger, 1984; Newberry and Nicoll, 1984; Thalmann, 1984; Kehl and McLennan, 1985; Hablitz and Thalmann, 1987). Evidence has been presented that the late IPSP conductance is transmitter-gated (Hablitz and Thalmann, 1987) and that the transmitter is GABA acting via $\mathrm{GABA}_{\mathrm{B}}$ receptors (Newberry and Nicoll, 1985; Dutar and Nicoll, 1988; Hasuo and Gallagher, 1988). The purpose of these experiments was to determine whether a pertussis toxin-sensitive GTP-binding protein (Gprotein) may control the potassium conductance of the late IPSP. Such G-proteins have recently been shown to control other agonist-gated potassium conductances such as that activated by opioids and $\alpha_{2}$-noradrenergic agonists in locus coeruleus (Aghajanian and Wang, 1986), by adenosine Al agonists in striatal and hippocampal neurons (Trussell and Jackson, 1987), by $\mathrm{GABA}_{\mathrm{B}}$ and 5-HT1 $1_{\mathrm{A}}$ agonists in hippocampal CA1 neurons (Andrade et al., 1986), by muscarinic agonists in atrial cells (Codina et al., 1987b; Yatani et al., 1987a), and by somatostatin in a pituitary cell line (Codina et al., 1987a; Yatani et al., 1987b). In brain, this pertussis toxin-sensitive family of $\mathrm{G}$-proteins excludes $G_{s}$, which stimulates adenylyl cyclase, but includes $G_{i}$, which inhibits adenylyl cyclase, and also includes G-proteins that may not be coupled to adenylyl cyclase (see reviews by Gilman, 1987, and Birnbaumer et al., 1987).

Although these experiments were designed to gain information about the possible GTP-binding protein (G-protein) control of a specific synaptic potassium conductance, they have more general implications because previous studies of such linkages have employed artificial application of agonists (c.g., Aghajanian and Wang, 1986; Andrade et al., 1986; Codina et al., 1987a, b; Trussell and Jackson, 1987; Yatani et al., 1987a, b), in some cases to cultured cells (Codina et al, 1987a; Trussell and Jackson, 1987), or to enzyme-treated, acutely dissociated cells (Codina et al., 1987b; Yatani et al., 1987a). In such experiments, it could not be readily shown that the agonists were delivered according to a spatial distribution, time course, and concentration that would select the same complement of receptors as would the endogenously released agonist. For example, exogenously applied agonists could affect nonsynaptic receptors that do not participate in synaptic responses. Moreover, such potassium conductances in cultured cells may not be coupled as they are in more intact adult tissue. Although it is useful to assume that the aforementioned simplified systems are appropriate models for more nearly intact and mature ones, it would 
be timely to have evidence that this may indeed be the case. Accordingly, this study of the G-protein control of the late IPSP in the hippocampal slice provides information about a conductance that is activated by endogenous release of neurotransmitter in an in vitro system that is better defined developmentally and more nearly intact than several previously uscd systems.

Some of these results have been presented in brief form elsewhere (Thalmann, 1987; Thalmann and Grenet, 1987).

\section{Materials and Methods}

Experiments were performed on hippocampal slices taken from adult rats weighing 125-190 gm. Slices were prepared and maintained as described previously (Thalmann and Hershkowitz, 1985). Briefly, the brain was removed after cervical dislocation and decapitation; it was cooled in ice-cold oxygenated saline, and the hippocampus was dissected free. Transverse slices, nominally $400-550 \mu \mathrm{m}$ thick, were cut on a McIlwain tissue chopper and transferred to a chamber similar to that described by Haas et al. (1979). Temperature was maintained at 35$37^{\circ} \mathrm{C}$ while the slices were perfused $(0.5-1.5 \mathrm{ml} / \mathrm{min})$ with an oxygenated $\left(95 \% \mathrm{O}_{2}-5 \% \mathrm{CO}_{2}\right)$ artificial cerebrospinal fluid of the following composition (in mM): $124 \mathrm{NaCl}, 1.25 \mathrm{NaH}_{2} \mathrm{PO}_{4}, 3.5 \mathrm{KCl}, 4 \mathrm{CaCl}_{2}, 4 \mathrm{MgSO}_{4}$, $26 \mathrm{NaHCO}_{3}$, and 10 glucose. The $\mathrm{pH}$ was $7.3-7.4$. These relatively high concentrations of divalent ions were included in some previous experiments in order to improve recording stability; this practice was continued for all experiments in this study because of 2 additional advantages that were found to obtain. First, it was possible to explore a wider range of late IPSP amplitudes without eliciting postsynaptic action potentials with their accompanying voltage-dependent conductances. Second, these ion concentrations resulted in a relatively lincar cellular slopc conductance between approximately -70 and $-120 \mathrm{mV}$. This linearity improved the accuracy of the necessary conductance estimates in these experiments. These estimates usually required the measurement of the voltage deflection caused by injection of a known current while the membrane potential was set near the reversal potential of either the late IPSP (approximately $-97 \mathrm{mV}$ ) or the early IPSP (approximately -75 $\mathrm{mV}$ ) (see description below).

Orthodromic activation was accomplished via $50 \mu \mathrm{sec}$ pulses delivered via a bipolar stimulating electrode placed either in the hilus of the dentate, just superior to the CA3 pyramidal cell layer, or in the granule cell layer of the dentate gyrus. The electrode location was varied until the site yielding the largest late IPSP was determined. Stimulus strength was generally adjusted so that action potentials were not evoked at the resting membrane potential.

Intracellular recordings were made with a bridge circuit amplifier (Getting 5A) via glass microelectrodes filled with $4 \mathrm{M} \mathrm{K}$-acetate. Bridge balance was continuously monitored using the voltage defiection produced by a 0.25 or $0.50 \mathrm{nA}$ test pulse and monitored at a $10 \mathrm{msec} / \mathrm{cm}$ oscilloscope sweep speed (for additional details, see Hablitz and Thalmann, 1987).

The increment in cellular conductance during the late IPSP was estimated by 2 methods. The first applied Ohm's law to the voltage deflection that was produced by a current pulse $(0.5 \mathrm{nA}, 100 \mathrm{msec})$ injected by the intracellular recording electrode. The conductance increment was given by the difference between the conductance before and during the late IPSP. For such measurements (as illustrated in Fig. $3, A, B$ ) the membrane potential was set at $-95 \pm 5 \mathrm{mV}$, near the normal reversal potential of the latc IPSP, and depolarizing pulses were administered such that the membrane potential traversed a range for which the slope conductance was relatively constant (Fig. $1 C, 8 E$ ). The deffections produced by these depolarizing pulses were measured $240 \mathrm{msec}$ following the mossy fiber stimulus, a time point that seemed to follow the normal tail of the early IPSP even at the most intense stimuli employed. The second method employed a similar logic, but the membrane potential displacement was provided by a continuous injection of current before and during the synaptic potentials. The displacement in membrane potential was measured before and $240 \mathrm{msec}$ after the mossy fiber stimulus. In an early series of 10 neurons, the conductance increment estimated by the first method $(13.1 \pm 6.5 \mathrm{nS}$, mean $\pm \mathrm{SD})$ was' similar to that estimated by the second method $(14.0 \pm 6.5 \mathrm{nS})$. The conductance increment during the early IPSP ( $25 \mathrm{msec}$ following the stimulus) was cstimated only by the sccond method.

Pertussis toxin was injected in the dorsal right hippocampus by 2 methods. In the first method, similar to the method of Aghajanian and Wang (1986), $2.4 \mu \mathrm{g}$ of pertussis toxin dissolved in $5 \mu \mathrm{l}$ of $50 \mathrm{mM} \mathrm{NaCl}$ and $1 \mathrm{~mm}$ EDTA buffered with $1 \mathrm{mM}$ Na-HEPES ( $\mathrm{pH} 7.3$ ) was injected over 20-30 min in rats anesthetized with pentobarbital anesthesia. Slices were harvested for recording $3 \mathrm{~d}$ following the injection. Two rats were injected in this way, and 3 control rats were injected similarly with the buffer not containing toxin. Subsequent rats were injected by the second method, that is, without anesthesia via a 30 gauge cannula that had been implanted under pentobarbital anesthesia at least a week prior to injection. Results of both methods were similar.

Pertussis toxin ADP-ribosylation of its substrate by the toxin injection was verified by an assay of membranes made from slices adjacent to those used for recording and frozen immediately after slicing (RibieroNeto et al., 1987).

GTP $\gamma \mathrm{S}$ was dissolved to a concentration of $14 \mathrm{~mm}$ in $2 \mathrm{M} \mathrm{K}$-acetate that had been adjusted to $\mathrm{pH} 7.3$ with acetic acid. Pertussis toxin was given by Dr. Ronald Sekura, National Institutes of Health, and prior to use, was dialyzed against the HEPES buffer described above. 4,5,6,7Tetrahydroisoxazolo-(5,4-C)-pyridin-3-ol (THIP) was given by Dr. P. Krogsgaard-Larsen and by $\mathrm{H}$. Lundbeck and $\mathrm{Co}$.; the baclofen by CibaGeigy. GTP $\gamma \mathrm{S}$ was purchased from Boehringer-Mannheim.

\section{Results}

The general features of the early and late IPSP in CA3 neurons under control conditions were similar to those described previously by this laboratory (Thalmann, 1984; Hablitz and Thalmann, 1987), namely, the early IPSP peaked within 20-25 msec following the mossy fiber stimulus, while the late IPSP peaked 150-200 msec following the mossy fiber stimulus and decayed to baseline within $1 \mathrm{sec}$ (Fig. $1 A$, left). The early IPSP reversed at $-73.4 \pm 3.9 \mathrm{mV}(n=26)$ (see Fig. $1, A, B$, left), while the late IPSP reversed approximately $25 \mathrm{mV}$ negative to this membrane potential, at $-98.8 \pm 3.1 \mathrm{mV}(n=16)$ (Fig. $1, A, B$, left). Consistent with the relative voltage insensitivity of the current underlying the late IPSP over the range of membrane potentials that could be explored here (Hablitz and Thalmann, 1987), the function relating the late IPSP amplitude to membrane potential was linear (Fig. 1 $B$, left) over the same range of membrane potentials for which the slope resistance of the neuron was also linear (Fig. $1 C$, left). In the illustrated case (Fig. 1, B, C, left), this range extended from approximately -75 to $-120 \mathrm{mV}$.

\section{Effect of pertussis toxin on the late IPSP}

The in vivo injection of pertussis toxin resulted in the ADPribosylation of a significant but not total portion of the toxin substrates in hippocampus, as shown by autoradiographs of the ${ }^{32} \mathrm{P}$-labeled pertussis toxin substrates (approximately 40,000 in apparent molecular weight) on polyacrylamide gels (Fig. 2). Note that there was also a marked degree of ADP-ribosylation in the hippocampal tissue contralateral to the injection site (Fig. 2, lane 1 versus 3 ).

In neurons from hippocampal tissue exposed to pertussis toxin, the late IPSP was reduced or absent. This could be seen most clearly near the reversal potential of the early IPSP, where the peak and decay of the late IPSP were evident in control neurons (Fig. $1 A,-78$ ) but absent in the typical toxin-treated neuron (Fig. $1 A,-75$ ). Table 1 summarizes these measurements in 26 control neurons and 21 toxin-exposed neurons. When synaptic responses were elicited near the resting potential in toxin-treated neurons, a small hyperpolarization could often be detected where late IPSP parameters were measured, some $200-240 \mathrm{msec}$ following the stimulus (Fig. $1 A$, right, -62 ). It was not possible to measure the reversal potential of this attenuated response consistently. However, in the majority of cases in which a reversal 
A
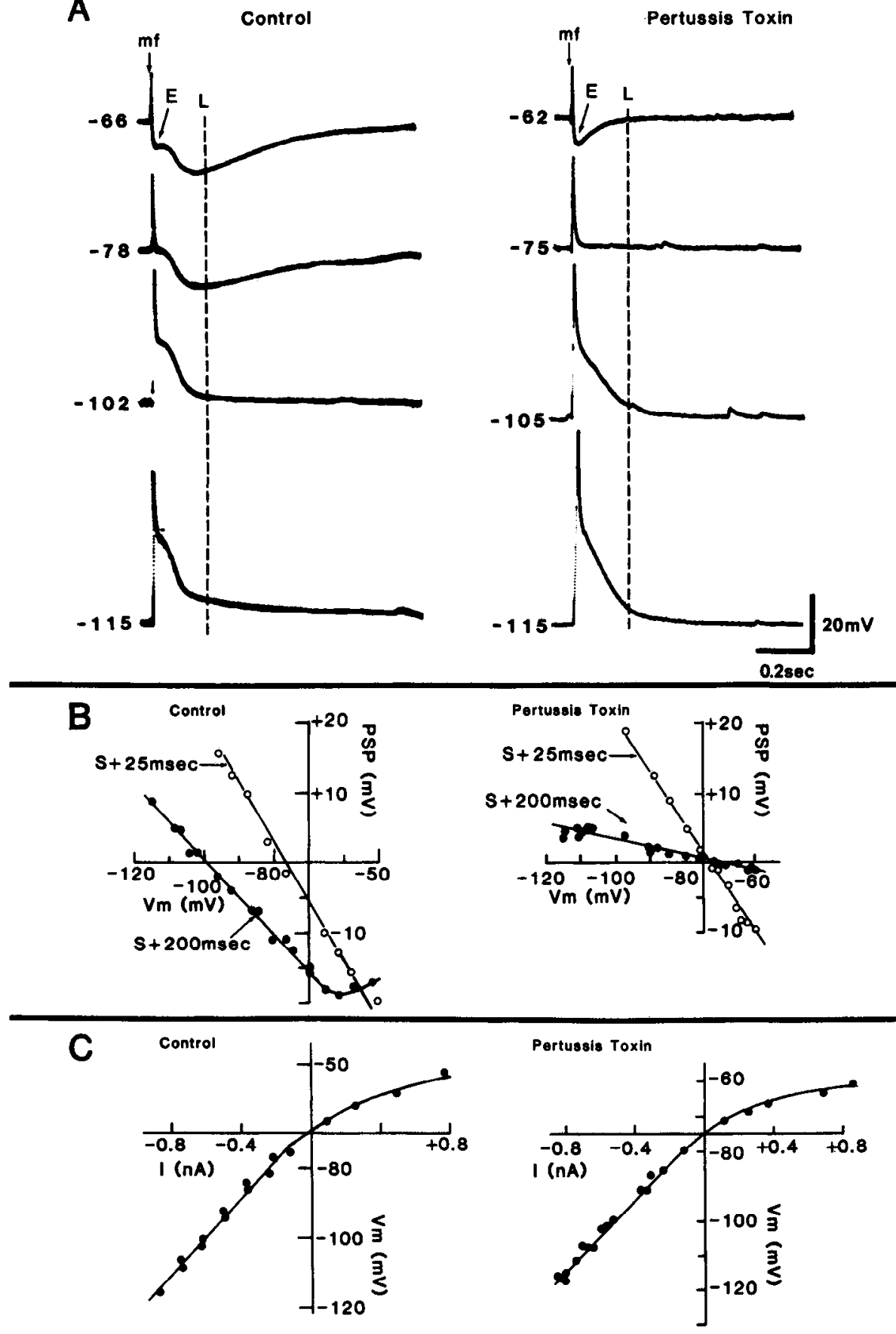

Figure 1. Pertussis toxin blocks the late, but not the early, IPSP. $A$, Numbers beside each trace denote the membrane potential at which the response to mossy fiber $(m f)$ stimulation was elicited. $E$ denotes the early IPSP and the dotted line $(L)$ indicates the point at which the late IPSP was measured for the graphs in $B .-66,-62 \mathrm{mV}$ : Approximately $10 \mathrm{mV}$ positive to the reversal potential of the early IPSP in the 2 cells. $-78,-75 \mathrm{mV}$ : Near the reversal potential of the early IPSP. Note the blockade of the late IPSP in the pertussis-treated cell. $-102,-105 \mathrm{mV}$ : Near the normal reversal potential of the late IPSP. $-115,-115 \mathrm{mV}$ : Negative to the normal reversal potential of the late IPSP. $B$, Graph of experiments in $A$. Curves were fit according to the assumption of linearity between -120 and $-75 \mathrm{mV}$ (least-squares linear regression) and by eye at membrane potentials positive to $-75 \mathrm{mV}$. The late IPSP in the toxin-treated cell, however, was fit to $-60 \mathrm{mV}$ according to the assumption of linearity. Note that in the toxin-treated cell, the early IPSP reversed at $-72 \mathrm{mV}$, and the small response at the time of the late IPSP reversed at $-69 \mathrm{mV}$. C, Current-voltage plots for same 2 neurons as in $B$. Membrane potential was measured immediately prior to mossy fiber stimulus. Curves were fit according to the assumption of linearity between -120 and $-75 \mathrm{mV}$ (least-squares linear regression) and by eye at membrane potentials positive to $-75 \mathrm{mV}$. potential could be determined, it was more typical of the early than of the late IPSP (Fig. 1, $A, B$, right).

In contrast to the severe attenuation of the late IPSP in toxintreated neurons, the early IPSP was present (Fig. 1, $A, B$ ) and had a normal reversal potential (Table 1). Although the peak hyperpolarization of the early IPSP elicited at the resting potential was highly variable, owing to the small difference of approximately $5 \mathrm{mV}$ between the resting potential and the $E_{\text {early }}$ IPSP, depolarization of the neuron invariably exposed a robust early IPSP in toxin-treated neurons. This is illustrated in the top traces of Figure $1 A(-66,-62)$, where the driving force upon the early IPSP in both control and toxin-exposed neurons was approximately $10 \mathrm{mV}$ (Fig. $1 B$ ).

\section{Effect of pertussis toxin on conductance during late IPSP}

The reduction of the late IPSP could be explained by an increase in another conductance with a more positive equilibrium potential. However, this explanation was ruled out by measurements of the conductance increment during the late IPSP (described in Materials and Methods and illustrated in Fig. 3, $A$, $B$ ), which showed that exposure to the toxin was associated with a profound reduction in this conductance increment (see Table 2).

In some neurons, the late IPSP conductance was determined as a function of several stimulus intensities. For these measurements, an index of synaptic excitation was defined that could 


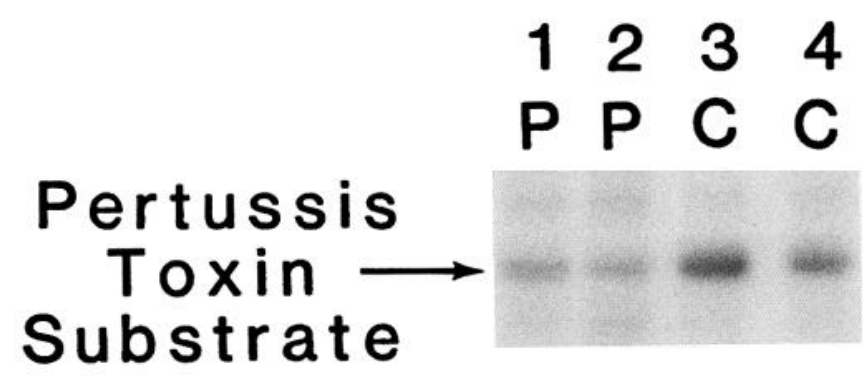

Figure 2. Pertussis toxin injection ADP-ribosylated its substrate in hippocampal slices. Lane 1, Pertussis toxin-injected brain slices were contralateral to injected hippocampus. Lane 2, Pertussis toxin-injected brain slices were ipsilateral to toxin injection. Lane 3, Control slices contralateral to injected side. Lane 4, Control slices from injected side.

provide graded information about the excitatory drive upon these neurons and presumably upon the circuits of the IPSPs. This latter measure was the slope of the rising phase of the mossy fiber excitatory postsynaptic potential (EPSP) between $25 \%$ and $65 \%$ of the EPSP peak (Fig. $3 C$ ). At mossy fiber stimulus intensities that were near threshold for eliciting a postsynaptic action potential (threshold was defined at a membrane potential of $-75 \pm 5 \mathrm{mV}$ ), this portion of the EPSP usually occurred within $2.0 \mathrm{msec}$ of the apparent onset of the EPSP (Fig. 3C), before the early IPSP is prominent (Andersen et al., 1964). Following the most intense mossy fiber stimuli used in these experiments $(100 \mathrm{~V})$, this portion of the EPSP usually occurred even earlier, within $1.0 \mathrm{msec}$ of the EPSP onset (Fig. 3C).

In control neurons, the EPSP slope varied from $21.4 \pm 9.2$ $\mathrm{mV} / \mathrm{msec}(n=8)$ at the threshold for a postsynaptic action potential (threshold determined as described in Materials and Methods) to $40 \pm 1.4 \mathrm{mV} / \mathrm{msec}(n=4)$ in response to the most intense mossy fiber stimulus $(100 \mathrm{~V})$ (Fig. $3 D)$. Over the same range of stimulus intensities, the late IPSP conductance in these neurons varied from $20.0 \pm 2.7 \mathrm{nS}$ to a maximum of $30.0 \pm$ $4 \mathrm{nS}$ (Fig. 3D). Note that in the illustrated neuron, the late IPSP conductance approached a maximum at a lower stimulus intensity $(40 \mathrm{~V})$ than did the EPSP. In toxin-treated neurons, the EPSP slope varied similarly to that of controls, from $22.9 \pm$ $9.1 \mathrm{mV} / \mathrm{msec}(n=8)$ (Fig. $3 E)$ near threshold to $40.8 \pm 0.8$

Table 1. Effect of pertussis toxin and GTP $\gamma \mathrm{S}$ on the late IPSP measured near the reversal potential of the early IPSP ( $\left.E_{\text {early IPSP }}\right)$

\begin{tabular}{clll} 
Experiment & $\begin{array}{l}E_{\text {early IPSP }} \\
(\mathrm{mV})\end{array}$ & $\begin{array}{l}\text { Cellular input } \\
\text { resistance } \\
(\mathrm{M} \Omega)\end{array}$ & $\begin{array}{l}\text { Late IPSP } \\
\text { amplitude } \\
(\mathrm{mV})\end{array}$ \\
\hline $\begin{array}{c}\text { Control } \\
n=26\end{array}$ & $-73.4 \pm 3.9$ & $40.0+8.6$ & $-12.4 \pm 2.4$ \\
$\begin{array}{c}\text { Toxin }(3 \mathrm{~d}) \\
n=17\end{array}$ & $-72.5 \pm 4.7$ & $37.3 \pm 3.4$ & $-0.3 \pm 1.2^{a}$ \\
$\begin{array}{c}\text { Toxin }(1 \mathrm{~d}) \\
n=4\end{array}$ & $-74.0 \pm 3.0$ & $37.8 \pm 3.3$ & $-4.0 \pm 1.1^{a}$ \\
$\begin{array}{c}\mathrm{GTP} \gamma \mathrm{S} \\
n=22\end{array}$ & $-75.0 \pm 1.7$ & $23.5 \pm 5.3^{a}$ & $-0.8 \pm 1.5^{a}$
\end{tabular}

$\overline{\text { All values given as means } \pm \text { SD. } n=\text { neurons. The late IPSP was measured near }}$ the reversal potential of the early IPSP.

${ }^{a}$ Different from control $p>0.001$. No other values were significantly different from control $(p<0.05)$. This and all subsequent $p$ estimates were given by a $t$ test for the difference between 2 unmatched groups.
Table 2. Effect of pertussis toxin and GTP $\gamma \mathrm{S}$ on conductance during the late IPSP

\begin{tabular}{lll} 
Experiment & $\begin{array}{l}\text { Input resistance } \\
(\mathrm{M} \Omega)\end{array}$ & $\begin{array}{l}\Delta g_{\text {late IPSP }} \\
(\mathrm{nS})\end{array}$ \\
\hline $\begin{array}{l}\text { Control } \\
n=23\end{array}$ & $37.9 \pm 8.3$ & $18.1 \pm 4.5$ \\
$\begin{array}{c}\text { Toxin }(3 \mathrm{~d}) \\
n=17\end{array}$ & $38.0 \pm 10.0$ & $1.7 \pm 1.1^{a}$ \\
$\begin{array}{c}\text { Toxin }(1 \mathrm{~d}) \\
n=4\end{array}$ & $38.2 \pm 6.2$ & $3.5 \pm 3.0^{a}$ \\
$\begin{array}{c}\mathrm{GTP} \gamma \mathrm{S} \\
n=17\end{array}$ & $21.3 \pm 4.1^{a}$ & \\
\hline
\end{tabular}

Input resistance and the conductance during the late IPSP $\left(\Delta g_{\text {latelPsP }}\right)$ were measured when the membrane potential was adjusted to $-95 \pm 5 \mathrm{mV}$. See text for more details.

${ }^{a}$ Different from control $(p<0.001)$.

$\mathrm{mV} / \mathrm{msec}(n=4)$ in response to a $100 \mathrm{~V}$ stimulus (Fig. $3 E$ ). However, in these same toxin-treated neurons, the conductance during the late IPSP was markedly reduced relative to control (Fig. $3 E$ ), varying from $2.2 \pm 0.7 \mathrm{nS}$ at threshold stimuli to only $5.4 \pm 2.2 \mathrm{nS}$ following a $100 \mathrm{~V}$ stimulus.

In order to examine the conductance of the late IPSP as a more direct function of the mossy fiber excitatory drive, the late IPSP conductance was also plotted as a function of EPSP slope rather than as a function of the intensity of the electrical pulse that elicited the EPSP. This is illustrated in Figure $3 F$ for the 2 neurons depicted in panels $A-E$ and in Figure $3 G$ for 8 control neurons and 10 toxin-treated neurons.

As suggested by the previous data, in control neurons, the late IPSP conductance approached a maximum in response to stimuli that produced EPSP slopes of approximately $25 \mathrm{mV} /$ $\mathrm{msec}$. At more rapid EPSP slopes, and thus at presumably greater amounts of synchronous excitation, there was no longer a concomitant increase in this inhibitory conductance. In toxintreated neurons, the late IPSP conductance was reduced relative to control at all measured EPSP slopes. Even at EPSP slopes of $40 \mathrm{mV} / \mathrm{msec}$ or greater, considerably in excess of those associated with maximal late IPSP conductances in control neurons, the late IPSP conductance was only $4.6 \pm 2.0 \mathrm{nS}(n=6)$.

\section{Lack of effect of pertussis toxin on early IPSP}

In contrast to the depression of the late IPSP in toxin-treated neurons, the early IPSP remained robust, as suggested by its amplitude when it was elicited either positive or negative to its reversal potential (Fig. 1, $A, B$ ). To gain additional information about the possible effect of the toxin upon the early IPSP, the conductance near the peak of the early IPSP was estimated as described in Materials and Methods. These results are summarized in Table 3. Clearly, the early IPSP in pertussis toxintreated cells did not suffer the same reduction as the late IPSP, and indeed, the average early IPSP conductance estimates were similar in control and in toxin-treated neurons (see Table 3).

\section{Pertussis toxin-insensitive response during late IPSP}

Certain of these data are relevant to the ionic basis of the small conductance that remained at the time of the late IPSP in toxintreated cells. As already mentioned, when the reversal potential of this remaining response could be measured, it was often positive to that of the normal late IPSP. This shift in reversal 

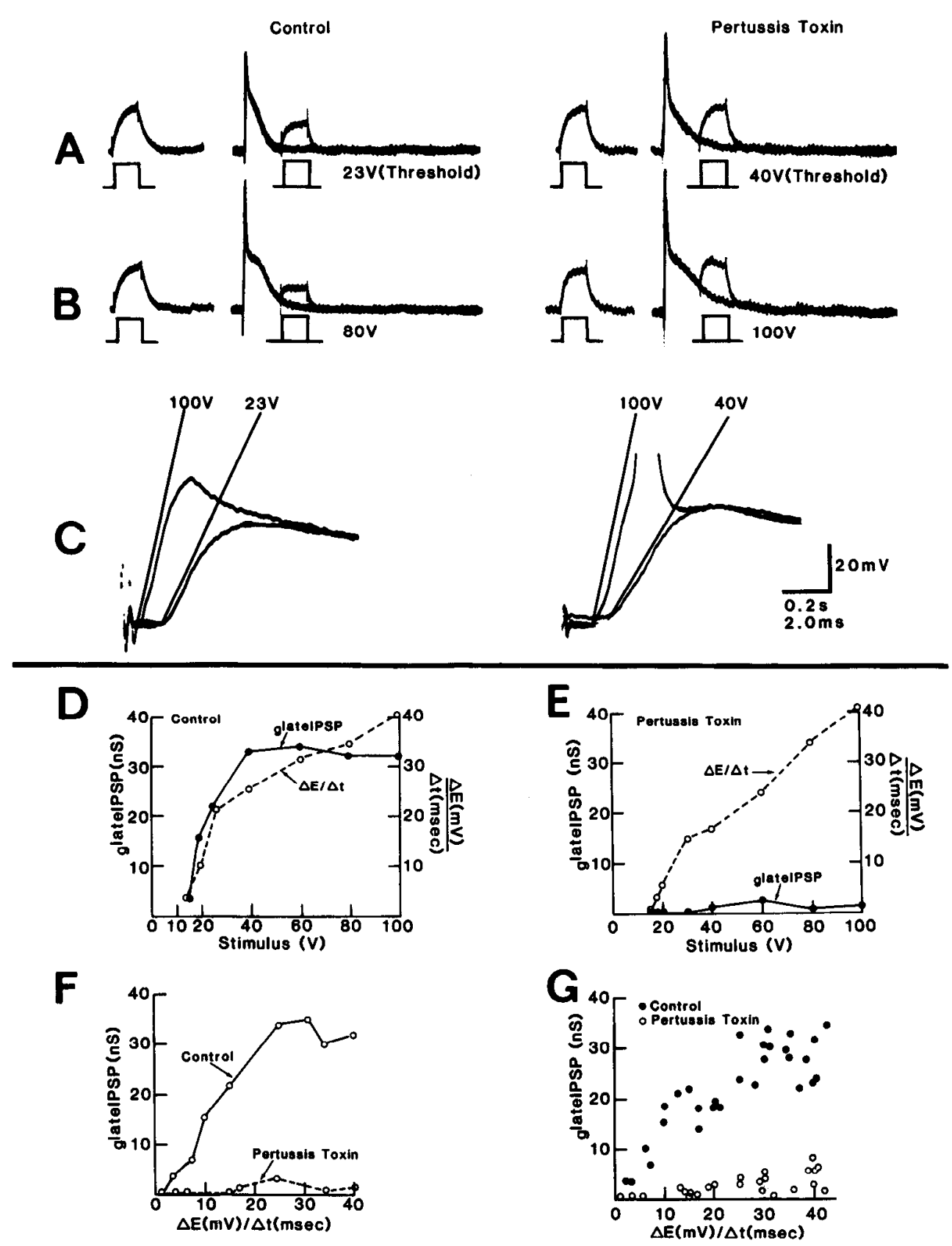

Figure 3. Late IPSP conductance as a function of stimulus intensity and EPSP slope. All records were made after the membrane potential had been adjusted to $-95 \pm 5 \mathrm{mV}$, near the normal reversal potential of the late IPSP. $A$ and $B$ illustrate the paradigms for measurement of the conductance increment during the late IPSP. A: Upper trace, voltage; lower trace, $0.5 \mathrm{nA}$ current pulses were injected as indicated. Cellular resistance was calculated from the voltage deflection at the end of each current pulse as described in the text. Left, Response of control neuron to $23 \mathrm{~V}$ mossy fiber stimulus, near the threshold for elicitation of a postsynaptic action potential in this neuron (threshold was determined earlier, when the membrane potential was set at approximately $75 \mathrm{mV}$; see text for further details). Right, Response of pertussis toxin-treated neuron to a threshold mossy fiber stimulus. This threshold in toxin-treated cells $(29.6 \pm 8.3 \mathrm{~V} ; n=11)$ did not differ systematically from control neurons $(34.3 \pm 12.6$ $\mathrm{V} ; n-23)$. $B$, Response of same neurons as in $A$ to more intense mossy fiber stimuli. Left, The $80 \mathrm{~V}$ stimulus for the control neuron elicited a maximal late IPSP conductance (see D). Right, A $100 \mathrm{~V}$ stimulus was the most intense employed. $C$, EPSPs in same neurons as in $A$ and $B$ in response to mossy fiber stimulation (fast sweep speed). Left, Control neuron. (23V) and $(100 \mathrm{~V})$ denote the straight lines fit by eye to EPSPs elicited by a $23 \mathrm{~V}$ and by a $100 \mathrm{~V}$ mossy fiber stimulus (see text for more details). These fits gave the EPSP slopes plotted in $D-G$. Right, Pertussis toxintreated neuron shown in $A$ and $B . D$. Same control neuron as in $A-C$. EPSP slope $(\Delta E / \Delta t)$ and conductance increment during the late IPSP as a function of the mossy fiber stimulus in volts $(V)$. Note that with increasing stimulus intensity, the late IPSP conductance approached a maximum at $40 \mathrm{~V}$, but the EPSP slope continued to increase. $E$, Same pertussis toxin-treated cell as in $A-C$, plotted as in $D$. $F$, Same 2 neurons as in $A-E$. Late IPSP conductance plotted as a function of EPSP slope. $G$, Plot as in $F$ of results from control neurons and pertussis toxin-treated neurons. Note that the control late IPSP conductance appeared similar at EPSP slopes of 25 and $40 \mathrm{mV} / \mathrm{msec}$. 


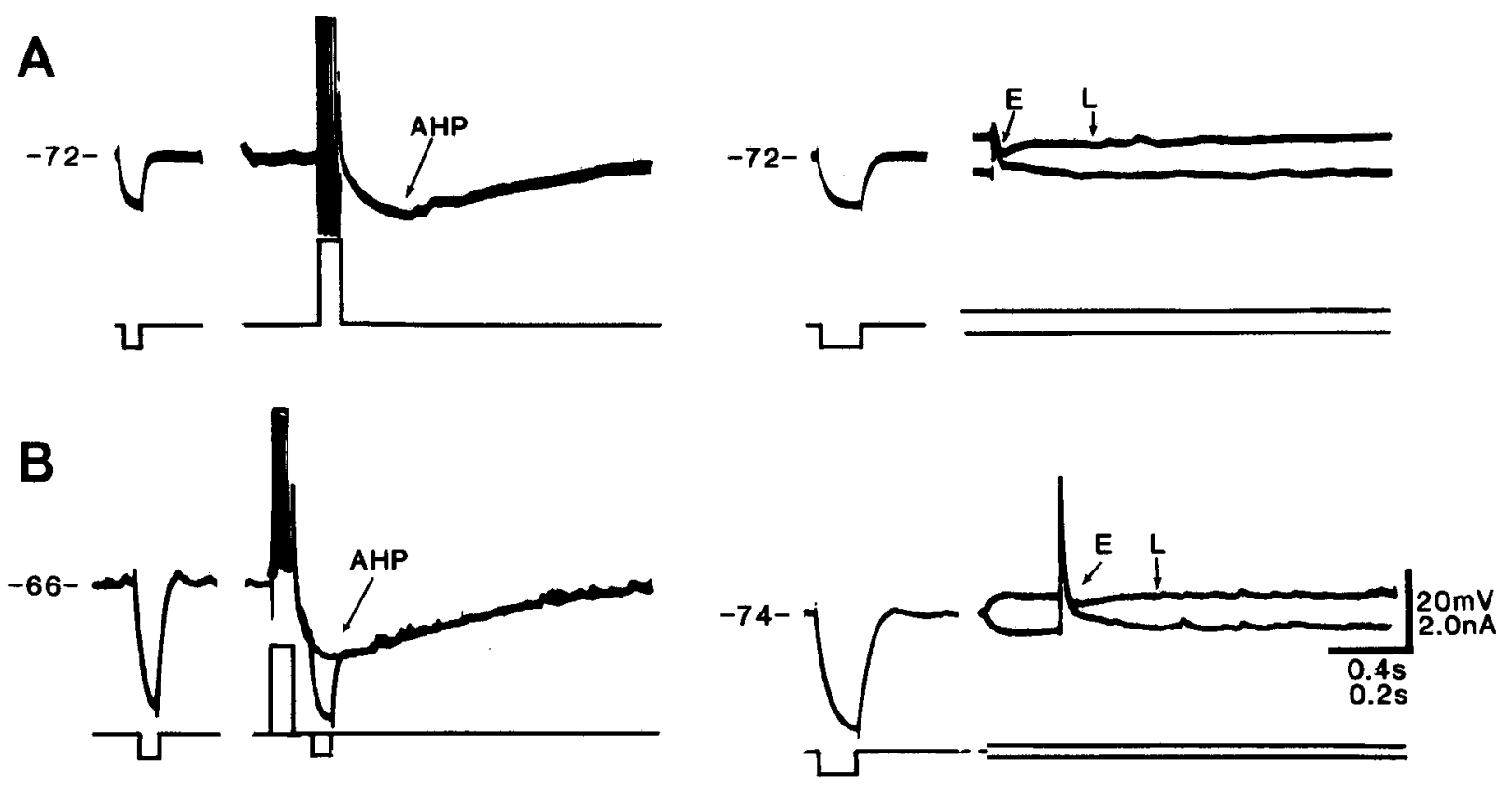

Figure 4. Reversal potential of the slow AHP in pertussis toxin-treated neurons is probably negative to $-90 \mathrm{mV}$. A: Left, Upper trace is membrane potential. The $-72 \mathrm{mV}$ level is the resting potential at which the AHP was elicited. Lower trace, Current injection through recording electrode. Right, A mossy fiber stimulus elicited an early IPSP reversing near $-72 \mathrm{mV}$ and a minimal response at a time when the late IPSP $(L)$ is normally prominent. The late IPSP conductance measured at $-95 \mathrm{mV}$ in this neuron (as described previously) was $0.5 \mathrm{nS}$. $B$, Different neuron. Left, Resting potential was near $-66 \mathrm{mV}$. Right, The early IPSP and the small response at the time of the late IPSP reversed at approximately $-74 \mathrm{mV}$. Late IPSP conductance in this neuron was $2.0 \mathrm{nS}$. Calibration: 0.45 refers to left; 0.25 , to right.

potential relative to control could be due to a potassium conductance if the toxin treatment had appropriately shifted the transmembrane potassium gradient. However, there is no precedent for such an effect, and experiments in 4 toxin-exposed neurons in which a large slow afterhyperpolarization (AHP) could be elicited by direct activation with current pulses near the resting potential further help to eliminate this explanation. Since such slow AHPs are primarily calcium-activated potassium conductances (Lancaster and Adams, 1986), they could place limits upon the possible $E_{k}$ 's of the neurons in which they were elicited. In one of these experiments, the peak of the AHP was $-90 \mathrm{mV}$, some $18 \mathrm{mV}$ negative to the reversal potential of the early IPSP in the same neuron (Fig. 4A). In another neuron (Fig. $4 B$ ), the AHP peaked at $-83 \mathrm{mV}$ and its reversal potential, estimated according to the method of Adams and Brown (1975), was $-97 \mathrm{mV}$, some $23 \mathrm{mV}$ negative to the reversal potential of the early IPSP in the same neuron. Thus, the pertussis toxin treatment probably did not cause a positive shift in the $E_{k}$ that could account for as much as a $20 \mathrm{mV}$ change in the reversal potential of the late IPSP. More likely, the severe attenuation of the potassium conductance of the late IPSP allowed some remaining conductance or conductances to play a larger role in determining the reversal potential of the response.

In control neurons, increasing the stimulus intensity caused a lengthening of that portion of the synaptic response with an apparent reversal potential positive to $-95 \mathrm{mV}$ (Fig. 3, $A, B$, control). In toxin-treated neurons, this depolarization could encroach upon the measured portion of the late IPSP, particularly in response to intense stimuli (Fig. 3, $A, B$, right panels). Therefore, particularly following intense stimuli, a portion of the residual late IPSP conductance in toxin-exposed neurons may consist of trailing components of an earlier response. This depolarizing effect was also observed with neurons injected with GTP $\gamma$ S (see below).

\begin{tabular}{|c|c|c|c|c|c|}
\hline Experiment & $\begin{array}{l}\text { Resting potential } \\
(\mathrm{mV})\end{array}$ & $\begin{array}{l}\text { Cellular input } \\
\text { resistance } \\
(\mathrm{M} \Omega)\end{array}$ & $\begin{array}{l}\Delta g_{\text {early IPSP }} \\
(\mathrm{nS})\end{array}$ & $\begin{array}{l}\Delta g_{\text {late IPSP }} \\
(\mathrm{nS})\end{array}$ & $\begin{array}{l}\text { EPSP } \\
\text { slope, } \Delta E \\
(\mathrm{nS})\end{array}$ \\
\hline \multicolumn{6}{|l|}{ Control } \\
\hline$n=8$ & $-69.0 \pm 3.6$ & $34.0 \pm 7.4$ & $139 \pm 40$ & $17.8 \pm 4.1$ & $19.1 \pm 3.1$ \\
\hline \multicolumn{6}{|c|}{ Pertussis toxin } \\
\hline$n=7$ & $-66.7 \pm 4.5$ & $35.6 \pm 8.5$ & $134 \pm 45$ & $2.1 \pm 1.1^{a}$ & $22.9 \pm 7.2$ \\
\hline
\end{tabular}

Note that for EPSP slope values: control, $n=6$; pertussis toxin, $n-5$. Cellular input resistance was determined at the resting potential. The $g_{\text {late } 1 \text { PSP }}$, measured by the pulse method in the same neurons, was in good agreement with the above value (control $X=17.0 \pm 4.0 \mathrm{nS}$; pertussis toxin-exposed $X=2.0 \pm 1.3 \mathrm{nS}$ ). Only cells exposed to the toxin for $3 \mathrm{~d}$ were analyzed.

${ }^{a}$ Different from control $(p<0.001)$. 
A Control
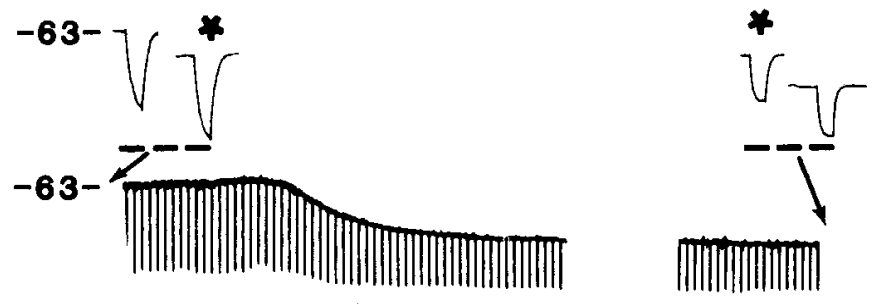

5uM Baclofen

\section{B Control}

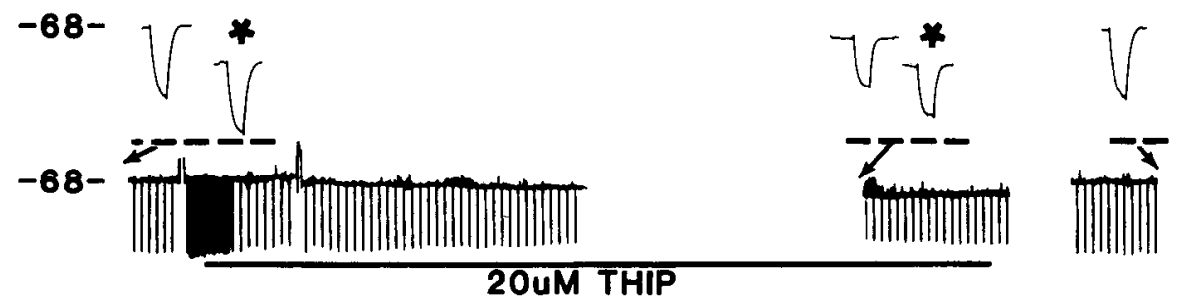

20UM THIP
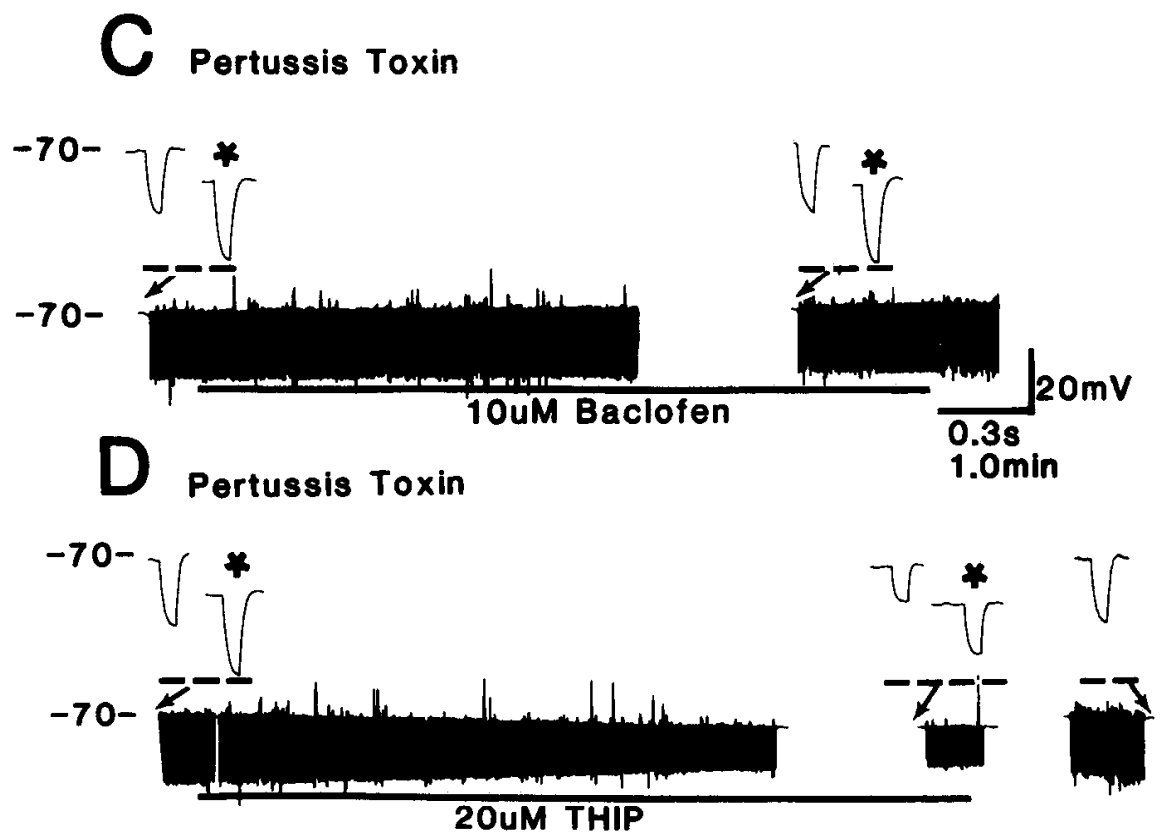

Figure 5. Effect of pertussis toxin on response to $\mathrm{GABA}_{\mathrm{A}}$ (THIP) or GABA (baclofen) agonists. $A$, Control neuron. Lower trace, Periodic deflections below the baseline were caused by hyperpolarizing pulses (100 msec, $0.5 \mathrm{nA}$ ) injected through the recording electrode. Baclofen, $5 \mu \mathrm{M}$, was perfused as indicated by the line beneath the voltage trace. Twenty minutes after cessation of baclofen, the cell approached its control membrane potential and resistance (record at far right). Upper trace, Responses to current pulses at a faster chart speed. Records were made at the approximate times indicated by the arrows. The asterisks indicate records when the membrane potential had been adjusted to $-71 \mathrm{mV}$ for the calculation of the conductance increment during the response; the current required for this adjustment was injected through the recording electrode. $B$, Different control neuron exposed to $20 \mu \mathrm{M}$ THIP. Resistance was measured in this case after the membrane potential had been adjusted to $-78 \mathrm{mV}$ (asterisks, upper traces ). Far right, THIP had been washed out for approximately $20 \mathrm{~min}$. $C$ and $D$, Pcrtussis toxin-treated neuron. Although this neuron did not respond to $10 \mu \mathrm{M}$ baclofen, it responded normally to perfusion of $20 \mu \mathrm{M}$ THIP. THIP perfusion was begun $30 \mathrm{~min}$ after cessation of baclofen perfusion. Record at far right, At 20 min after cessation of THIP perfusion, cell resistance and potential had returned to control values.

\section{Effect of baclofen and THIP}

Baclofen, an agonist for a putative receptor $\left(\mathrm{GABA}_{\mathrm{B}}\right)$ (Bowery et al., 1983) mediating the late IPSP (Newberry and Nicoll, 1985), was perfused until the response to the agonist approached an asymptote, usually 5-8 min after onset of perfusion. The conductance increment during the response was estimated from the voltage deflection produced by $0.5 \mathrm{nA}$ hyperpolarizing pulses before the response and during the peak response. A steady current injection was used to adjust the membrane potential to a fixed value for each measurement in a given cell $(-75 \pm 5$ $\mathrm{mV}$ ). The response to THIP, an agonist for the GABA $\mathrm{A}_{\mathrm{A}}$ receptor (Falch and Krogsgaard-Larsen, 1982) mediating the early IPSP, was measured in the same way. The paradigms for these measurements are illustrated in Figure 5, and a summary of several such experiments is shown in Figure 6. The response to 5 or 10 $\mu \mathrm{M}$ baclofen was significantly less in toxin-treated than in control neurons. By contrast, the response to 20 or $50 \mu \mathrm{M}$ THIP was similar in toxin-treated and control neurons. Thus, the toxin significantly reduced the response to $\mathrm{GABA}_{\mathrm{B}}$, but not a GA$\mathrm{BA}_{\mathrm{A}}$, agonist.

\section{Effect of GTP $\gamma$ S on late IPSP and its associated conductance}

To manipulate G-proteins in a manner that was restricted to the impaled postsynaptic neurons, the nonhydrolyzable GTP analog GTP $\gamma$ S was introduced directly into postsynaptic neurons via the recording pipette. This molecule was expected to activate G-proteins, including the putative G-protein controlling the late IPSP.

In most neurons impaled with GTP $\gamma$ S-containing electrodes, 

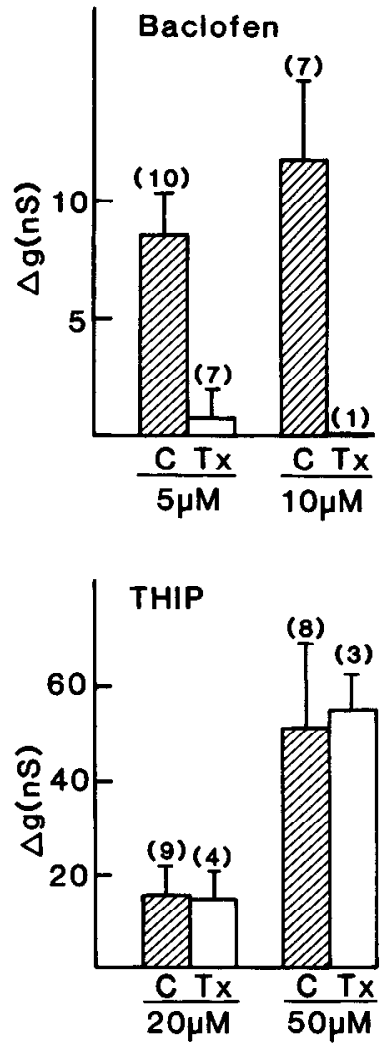

Figure 6. Graphic depiction of effect of pertussis toxin upon response to THIP or baclofen, measured according to the paradigm illustrated in Figure 5. Ordinate: increment in conductance is given in nanoSiemens $[\Delta g(\mathrm{nS})]$. Error bars denote the SD; number above each bar is the number of neurons exposed to a given treatment. $C$, control neurons; $T x$, neurons exposed to pertussis toxin. The response to 5 or $10 \mu \mathrm{M}$ baclofen (upper panel) was greatly depressed in pertussis toxin-treated cells, but the response to 20 or $50 \mu \mathrm{M}$ THIP (lower panel) was not affected by exposure to the toxin. The response of toxin-treated cells to $5 \mu \mathrm{M}$ baclofen differed significantly from control $(t=15.85 ; 15 d f ; p<0.001)$ the cellular potential was already more hyperpolarized and the cellular conductance was already greater than control by the time recording conditions had stabilized, suggesting that the molecule had already affected the cell. In a few neurons, however, these parameters were still near control values when recording conditions had stabilized. In these neurons (Fig. $7 A$ ), the membrane potential slowly hyperpolarized to a value that was negative to the reversal potential of the early IPSP. At the same time, the cellular conductance increased, and the late IPSP became less conspicuous. The effects of the GTP $\gamma \mathrm{S}$ were systematically measured in all neurons that had been impaled at least $12 \mathrm{~min}$. In such neurons, the conductance increment associated with the late IPSP was severely attenuated (Fig. $7 B$; Table 2), as was the voltage deflection of the late IPSP measured when the membrane potential was adjusted near the reversal potential of the early IPSP (Fig. $8 A-C$; Table 1). A conspicuous early IPSP invariably remained (Fig. $8 A-C$ ).

\section{GTP $S S$ activated a conductance similar to that associated with baclofen or the late IPSP}

The reversal potential and the amplitude of the ionic conductance activated by GTP $\gamma \mathrm{S}$ were estimated in order to compare this conductance with those associated with baclofen and with the late IPSP. Since the average membrane potential attained by GTP $\gamma$ S-injected neurons was $-80.2 \pm 3.0 \mathrm{mV}(n=20)$, some $5 \mathrm{mV}$ negative to the reversal potential of the chloridemediated late IPSP in the same neurons $(74.8 \pm 2.0 \mathrm{mV})$, it appeared likely that the reversal potential $\left(E_{\mathrm{GTP}_{2} \mathrm{~S}}\right)$ of this relatively small conductance (see below) (1) must be negative to $-80 \mathrm{mV}$ and (2) must include an ionic conductance with an equilibrium potential negative to that of chloride, namely, potassium. More accurate determination of $E_{\mathrm{GTP}, \mathrm{S}}$ by methods that required repeated application of the compound at different membrane potentials was precluded since the conductance, once activated, was present for the duration of impalement by the GTP $\gamma \mathrm{S}$ electrode. However, further information about $E_{\mathrm{GTP}_{\gamma} \mathrm{S}}$

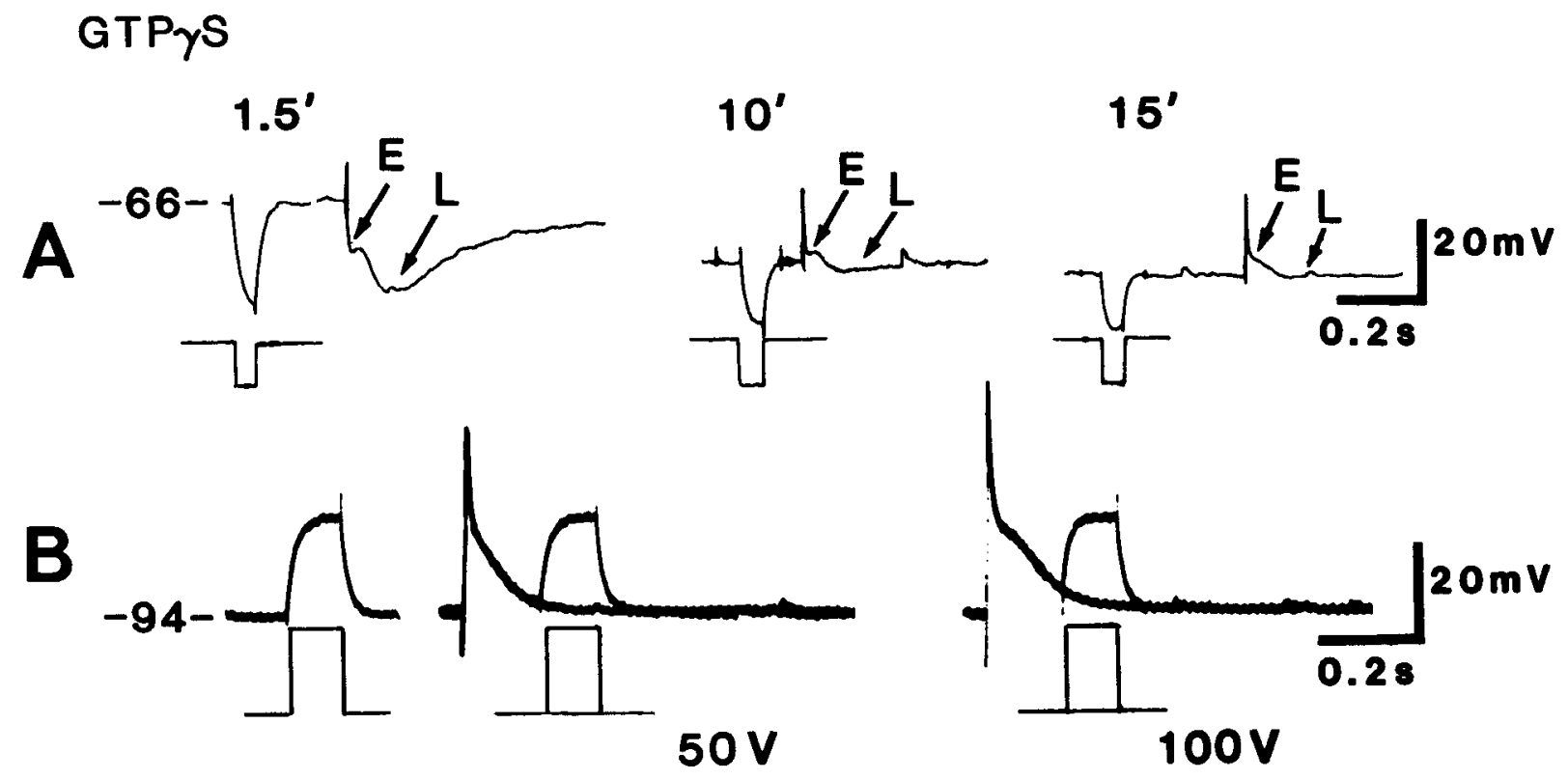

Figure 7. Efrect of GTP $\gamma$ S on cellular resting potential, resistance, and the late IPSP. A: Upper traces, Voltage recordings at 1.5, 10, and 15 min after impalement with an electrode containing $1.4 \mathrm{~mm} \mathrm{GTP} \gamma \mathrm{S}$; lower traces denote application of $0.5 \mathrm{nA}$ hyperpolarizing current pulses to reflect cellular resistance. $B$, Different neuron impaled with an electrode containing $14.0 \mathrm{~mm}$ GTP $\gamma \mathrm{S}$. Neither a $50 \mathrm{~V}$ mossy fiber stimulus (producing an EPSP rise time of approximately $20 \mathrm{mV} / \mathrm{msec}$ ) nor a $100 \mathrm{mV}$ stimulus (EPSP rise time, approximately $40 \mathrm{mV} / \mathrm{msec}$ ) produced much change in cellular resistance, measured $240 \mathrm{msec}$ after the stimulus. Lower trace indicates $0.8 \mathrm{nA}$ depolarizing pulses. 
was gained by estimating it according to the method of Adams and Brown (1975). Specifically,

$$
E_{\mathrm{GTPs}}=R P+\Delta E \frac{R_{c}}{R_{c}-R_{\mathrm{GTP} \gamma \mathrm{S}}},
$$

where $R P$ is the average resting potential of a sample of control neurons measured under stabilized recording conditions (Table 1); $\Delta E$ is the difference between $R P$ and the neuronal potential after exposure to GTP $\gamma \mathrm{S} ; R_{c}$ is the average resistance at -75 $\mathrm{mV}$ in the sample of control neurons; and $R_{\mathrm{GTP} \gamma \mathrm{S}}$ is the resistance of each GTP $\gamma \mathrm{S}$ exposed neuron, also measured at $-75 \mathrm{mV}$.

Although this method would not directly demonstrate the reversal in polarity of the response to GTP $\gamma \mathrm{S}$, several considerations indicate that the method was useful in the present context. First, the slow development of the GTP $\gamma S$ conductance and the relative constancy of cellular input conductance over the range of membrane potentials that was traversed in this estimate (Figs. $1 C, 8 E$ ) were favorable for the application of this method. More importantly, for comparison the same method was also used to estimate the reversal potential of the response to perfusion of the $\mathrm{GABA}_{\mathrm{B}}$ agonist baclofen, a response that, like the late IPSP (Nicoll and Alger, 1981; Thalmann and Ayala, 1982; Alger, 1984; Newberry and Nicoll, 1984; Thalmann, 1984; Kehl and McLennan, 1985a; Hablitz and Thalmann, 1987), is known to depend upon a potassium conductance (Gahwiler and Brown, 1985; Inoue et al., 1985; Newberry and Nicoll, 1985). The same method was also used to estimate the reversal potential of the response to perfusion of the $\mathrm{GABA}_{\mathrm{A}}$ agonist THIP, a response that, like the early IPSP, depends upon a chloride conductance (for additional references, see Alger and Nicoll, 1982).

Thus calculated in response to 100 or $500 \mu \mathrm{M}$ baclofen, $E_{\text {baclofen }}$ was $98.4 \pm 4.5 \mathrm{mV}(n=6)$, in good agreement with $E_{\text {late IPSP }}$ determined by more direct methods in these experiments (Fig. 1 , and first paragraph of Results). By contrast, $E_{\mathrm{TH} \text { IP }}$ in response to $50 \mu \mathrm{M}$ THIP was $75 \pm 3.4 \mathrm{mV}(n=11)$, in good agreement with $E_{\text {early IPSP }}$ determined by more direct methods (Table 3 ).

$E_{\mathrm{GTP \gamma}}$, determined as described, was $-98.4 \pm 13 \mathrm{mV}(n=$ $20) . E_{\mathrm{GTP}_{\gamma} \mathrm{S}}$ was also calculated using each neuron as its own control in cases where recording conditions had stabilized relatively quickly ( $<3$ min after impalement). On this basis, $E_{\mathrm{GTP}_{\gamma} \mathrm{s}}$ was $-100 \pm 9 \mathrm{mV}(n=10)$. Thus, each of these values was indistinguishable from $E_{\text {baclofen }}$ or $E_{\text {late IPSP. It therefore seems }}$ likely that the conductance activated by GTP $\gamma \mathrm{S}$ is similar to that associated with the response to baclofen and the late IPSP, that is, exclusively or predominantly a potassium conductance.

The amplitude of the conductance activated by GTP $\gamma \mathrm{S}$ was estimated at 2 different membrane potentials. Since most neurons already displayed the effects of GTP $\gamma S$ by the time recording conditions had stabilized, the average conductance and resting potential of the control neurons used to compile Tables 1 and 2 was taken as the best estimate of the control conductance and resting potential for each GTP $\gamma$ S-exposed neuron. Thus calculated, the GTP $\gamma \mathrm{S}$-activated conductance was similar whether the membrane potential had been adjusted by current injection to $-75 \mathrm{mV}(20.5 \pm 8.7 \mathrm{nS}, n=18)$ or to $-95 \mathrm{mV}$ $(21.9 \pm 7.7 \mathrm{nS}, n=16)$. At least within these narrow limits, this conductance displayed little or no rectification, in common with the conductance of the late IPSP in these neurons (Hablitz and Thalmann, 1987).
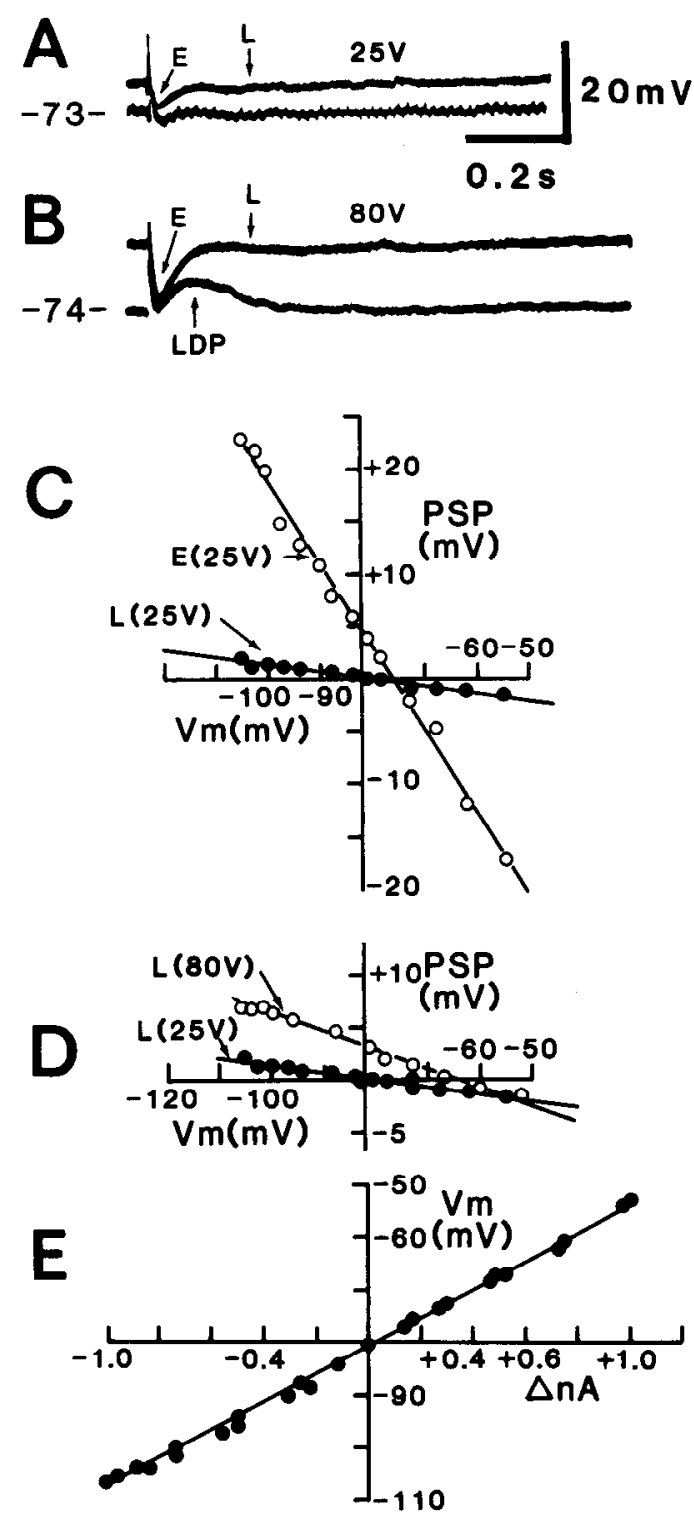

Figure 8. GTP $\gamma \mathrm{S}$-treated neuron. Responses at the time of early $(E)$ and late $(L)$ IPSPs in response to $25 \mathrm{~V}$ (approximately $20 \mathrm{mV} / \mathrm{msec}$ EPSP rise time) or to an $80 \mathrm{~V}$ (approximately $40 \mathrm{mV} / \mathrm{msec}$ EPSP rise time) mossy fiber stimulus. $A$, Response at the time of the early $(E)$ and late $(L)$ IPSP at 2 different membrane potentials $(-73$ and $-68 \mathrm{mV})$. The small response at $L$ was near its reversal potential at $-73 \mathrm{mV}$ but was slightly hyperpolarizing at $-68 \mathrm{mV}$. $B$, Near the reversal potential of the early IPSP $(-74 \mathrm{~V})$, an intense $(80 \mathrm{~V})$ stimulus elicited a late depolarizing potential (LDP) that was still present at the time of the usual peak of the late IPSP. The upper trace was initiated at $-62 \mathrm{mV}$, near the reversal potential at $(\mathrm{L})$ in response to this intense stimulus. $C$, Graphic depiction of early and late IPSPs in response to $25 \mathrm{~V}$ mossy fiber stimulus. Measurements were made at the approximate time points indicated by arrows in $A . D$. Effect of $25 \mathrm{~V}$ and $80 \mathrm{~V}$ stimulus upon the reversal potential at the time of the late IPSP. $E$, Current-voltage relation of the same neuron. The slope resistance was reduced relative to that of control neurons (see Fig. 1), but it was still constant in the membrane potential region where late IPSP conductance was measured. Functions in $C-E$ were fit according to the assumption of linearity by lcast-squares lincar regression.

\section{Effect of GTP $\gamma S$ on response to baclofen and THIP}

The effect of baclofen and THIP upon the GTP $\gamma$ S-injected neurons was examined as illustrated in Figure 9. The effect of 10 $\mu \mathrm{M}$ baclofen was reduced $(0.9 \pm 1.2 \mathrm{nS}, n=4)$, as was the 
Figure 9. Response of a GTP $\gamma \mathrm{S}$ injected neuron to THIP and baclofen (same neurons shown in Fig. $8 A$ ). Notation as in Figure 5. Lowest traces in $B$ show the mossy fiber response elicited before (left trace), 3 min after ( middle trace), and $8 \mathrm{~min}$ after (right trace) onset of baclofen perfusion. Note that although baclofen had little or no effect upon the membrane potential or resistance of the GTP $\gamma \mathrm{S}$ injected neuron, it most likely affected presynaptic neurons, as indicated by the blockade of the early IPSP $(E)$ soon after the onset of baclofen perfusion.
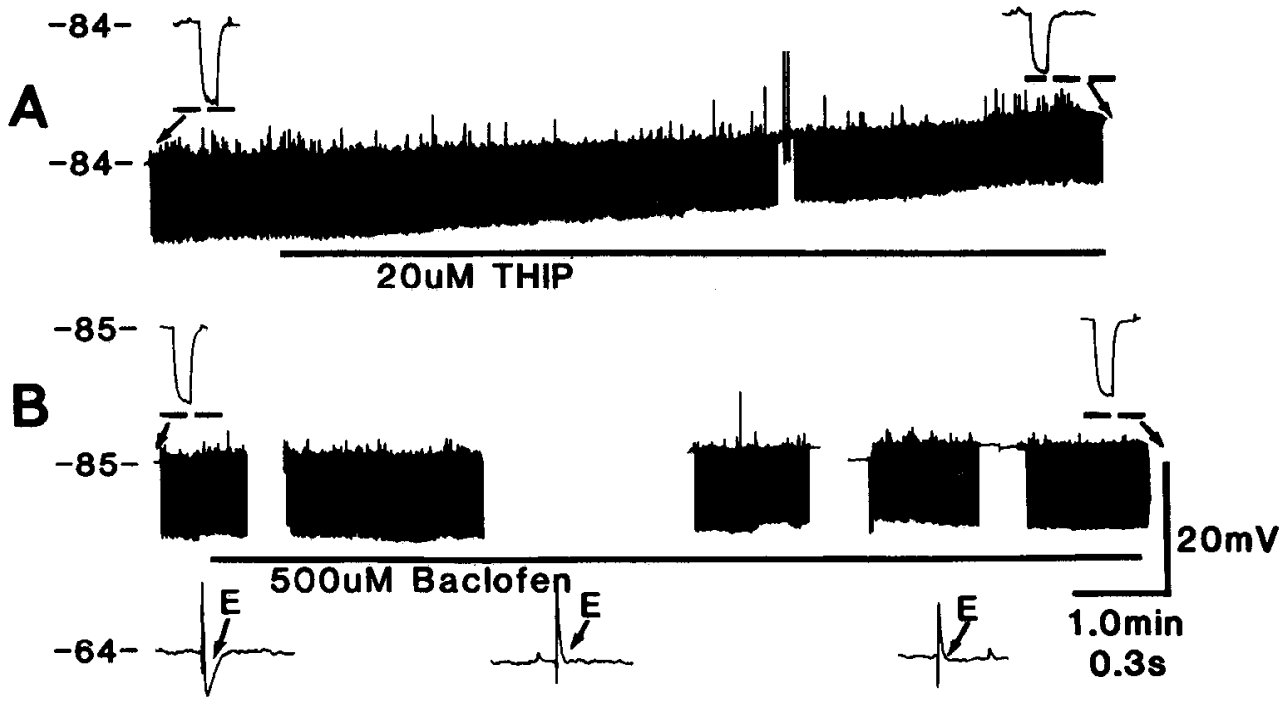

response to much higher concentrations (Fig. $9 B$ ), but a typical response to $20 \mu \mathrm{M}$ THIP could be rcadily demonstratcd (Fig. $9 \mathrm{~A}: 14.6 \pm 2.5 \mathrm{nS}, n=4)$ in the same neurons. Note that the response to THIP was typically depolarizing in GTP $\gamma \mathrm{S}$-injected neurons, since the membrane potential of these neurons was some $5 \mathrm{mV}$ negative to $E_{\mathrm{THIP}}$. In order to indicate the conductance increment associated with a maximal response to baclofen, large doses of baclofen were applied in a few experiments. Since the response to $100 \mu \mathrm{m}$ baclofen $(18.6 \pm 2.4 \mathrm{nS}, n=3)$ was only slightly less than that to $500 \mu \mathrm{M}$ baclofen $(19.3 \pm 2.7 \mathrm{nS}$, $n=3$ ), both doses were considered to elicit a near-maximal response. Thus, the amplitude of the conductance activated by GTP $\gamma$ S was similar to that associated with these high concentrations of baclofen and was approximately three-fourths of that associated with maximal late IPSPs.

\section{Does the GTP $\gamma S$ conductance shunt that of the late IPSP and baclofen?}

Several measurements were made to test the possibility that this blockade of responses by GTP $\gamma \mathrm{S}$ was due to shunting through the decreased resistance of the GTP $\gamma$ S-injected neurons. First, the amplitude of the late IPSP was analyzed in neurons that had been excluded from previous measurements because of their atypically low input resistances. Figure 10 shows these measurements, as well as the late IPSP amplitudes in GTP $\gamma$ S-exposed neurons, plotted as a function of cellular resistance. Not only were the late IPSPs of control neurons greater than those of the GTP $\gamma$ S-exposed neurons at all resistances, but the late IPSP was within approximately $10 \%$ of control values throughout most of the range of input resistances that were associated with exposure to GTP $\gamma \mathrm{S}$. Even in control neurons with lower input resistances than those of any GTP $\gamma \mathrm{S}$-injected neuron, the late IPSP was apparent (Fig. 10). In addition, the conductance increment during the late IPSP was measured in 4 control neurons with cellular resistances typical of those exposed to GTP $\gamma \mathrm{S}$ (23.2; range, $20-26 \mathrm{M} \Omega)$ and was found to be similar $(21.8 \pm$ $5.5 \mathrm{nS}$ ) to control (see Table 3). Thus, neurons with input resistances similar to those injected with GTP $\gamma \mathrm{S}$ showed little attenuation of the amplitude of the late IPSP, no detectable effect upon the conductance of the late IPSP, and no detectable effect upon the response to low doses of THIP (see above). Therefore, a simple shunting mechanism seems unlikely to ac- count for the GTP $\gamma$ S-associated blockade of the late IPSP and the response to baclofen.

\section{Nonadditivity of the conductance associated with GTP $\mathrm{S}$, the late IPSP, and baclofen}

In order to determine whether the 3 potassium conductances were additive, GTP $\gamma \mathrm{S}$ injections were combined with maximal doses of baclofen or with intense mossy fiber stimulation sufficient to elicit maximal late IPSPs in control neurons (EPSP rise times of $40 \mathrm{mV} / \mathrm{msec}$ ). As in the case of $10 \mu \mathrm{M}$ baclofen, 100 and $500 \mu \mathrm{M}$ baclofen added only a negligible conductance $(0.9 \pm 1.2 \mathrm{mV}, n=5)$ to that already activated by GTP $\gamma \mathrm{S}$ (Fig. $9 B$ ). Similarly, intense mossy fiber stimulation added a late IPSP conductance of only $3.9 \pm 1.5 \mathrm{nS}(n=9)$ in such neurons (Fig. $7 B$ ). In contrast to the nonadditivity of these effects, THIP (20 $\mu \mathrm{M})$ elicited similar conductance increments in either GTP $\gamma \mathrm{S}$ injected or control neurons (Fig. 9A). Figure 11 summarizes the results of experiments similar to these in which the same 5 GTP $\gamma$ S-injected neurons were exposed in turn to maximal late IPSP stimulation, high doses of baclofen, and $20 \mu \mathrm{M}$ THIP. This figure emphasizes that GTP $\gamma \mathrm{S}$ mostly or completely occluded the conductance normally associated with baclofen or the late IPSP.

\section{$G T P \gamma S$-insensitive conductance at the time of the late IPSP}

In response to intense mossy fiber stimulation, at least a portion of the GTP $\gamma \mathrm{S}$-insensitive conductance at the time of the late IPSP was probably not a potassium conductance but was a response unrelated to the late IPSP. As reported above, even threshold synaptic stimulation of pertussis toxin-treated neurons sometimes elicited a small response measurable 200-240 msec following the stimulus. This response reversed at a more positive level than the normal late IPSP (see Fig. 1). A similar response could also occur after threshold stimulation of GTP $\gamma$ Streated neurons (Fig. 8, $A, C$ ). More intense synaptic stimulation of pertussis toxin- or GTP $\gamma$ S-treated neurons usually elicited a frank depolarization (LDP) that had a faster time course than the late IPSP but that nevertheless persisted through the time points at which the late IPSP was measured and influenced the reversal potential at these time points. For example, in the GTP $\gamma$ S-injected ncuron illustrated in Figure 8, increasing the stimulus intensity from 25 to $80 \mathrm{~V}$ produced a depolarizing 


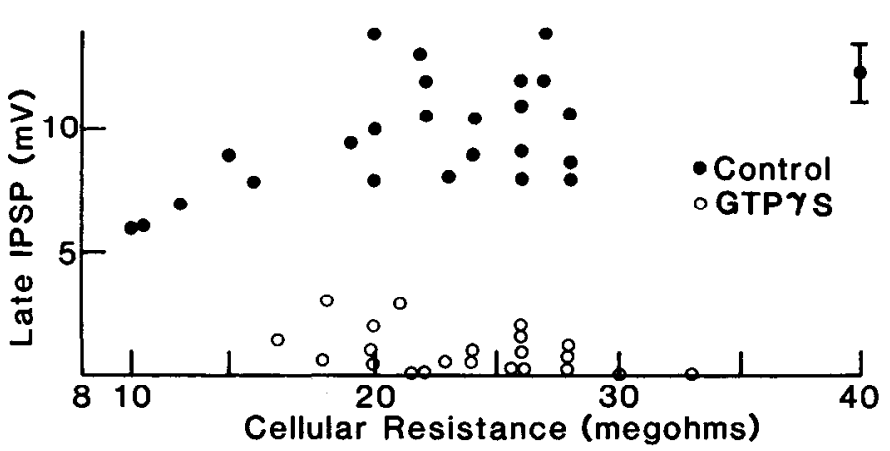

Figure 10. Late IPSP amplitudes in low-resistance control neurons and in GTP $\gamma \mathrm{S}$-injected neurons, plotted as a function of neuronal resistance. The mean and SD of the control neurons depicted in Table 1 is displayed for comparison (average resistance, $40 \mathrm{M} \Omega$ ). The latter control neurons all had resistances in excess of $30 \mathrm{M} \Omega$.

response (Fig. $8 B$, LDP) that reversed at $-66 \mathrm{mV}$ when measured $200 \mathrm{msec}$ after the stimulus (Fig. $8 D$ ). At its peak, the depolarizing response reversed at $63.4 \pm 1.2 \mathrm{mV}(n=8)$, more than $10 \mathrm{mV}$ positive to the reversal potential of the early IPSP in the same neurons $(75.2 \pm 0.8 \mathrm{mV})$ and more than $30 \mathrm{mV}$ positive to the reversal potential of the normal late IPSP.

Thus, at least a portion of the GTP $\gamma \mathrm{S}$ - and pertussis toxinresistant conductance at the time of the late IPSP was probably a separate response that did not depend upon an increased potassium conductance. This being the case, these 2 agents may block a larger proportion of the specific potassium conductance associated with the maximal late IPSP than the $75-80 \%$ indicated by the measurements of the total conductance increment at the time of the late IPSP. Similarly, the amplitude of the maximal potassium conductance that is gated by the late IPSP transmitter must be somewhat less than $30 \mathrm{nS}$ and may therefore correspond closely indeed with the amplitude of the conductance that can be activated by GTP $\gamma \mathrm{S}$ or baclofen.

\section{Discussion}

These experiments provide evidence that a pertussis toxin-sensitive G-protein controls the conductance associated with a synaptic response in brain, namely the late IPSP of hippocampal CA3 neurons. Thus, it was shown that 2 agents affecting G-proteins, pertussis toxin introduced into the hippocampus and GTP $\gamma$ S injected directly into the postsynaptic neuron, profoundly reduced the late IPSP without a similar effect upon either the mossy fiber-evoked EPSP or the early IPSP. Concomitantly, these compounds also blocked the response to an agonist for a putative receptor $\left(\mathrm{GABA}_{\mathrm{R}}\right)$ (Bowery et al., 1983) mediating the late IPSP (Newberry and Nicoll, 1985; Dutar and Nicoll, 1988), as also demonstrated in CA1 neurons (Andrade et al., 1986), but did not affect the response to an agonist for the receptor $\left(\mathrm{GABA}_{A}\right)$ mediating the early IPSP.

The in vivo toxin injections that produced this attenuation of the late IPSP were associated with the ADP-ribosylation of a marked amount of the total toxin substrate that was available to this cell-free assay. Although the assay did not allow a quantitative assessment of the toxin's effect upon its substrates, it is interesting that the treatment clearly did not ADP-ribosylate $100 \%$ of the substrates. As applied in vivo, pertussis toxin could only be internalized by cells having appropriate recognition sites (Tamura et al., 1982). Therefore, it is possible that the injected

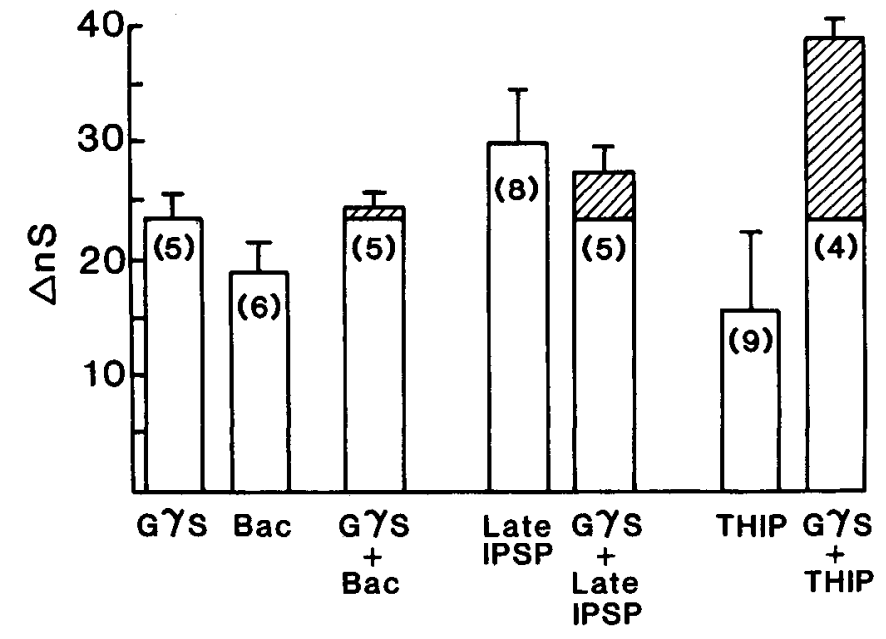

Figure 11. Nonadditivity of the conductances associated with GTP $\gamma$ S, baclofen, and the late IPSP. Ordinate, Conductance increment associated with each agent; numbers in each bar denote number of neurons subjected to each condition. The error line above each bar denotes SD. The same 5 neurons were injected with GTP $\gamma \mathrm{S}(\mathrm{G} \gamma \mathrm{S})$ and then exposed to the other 3 treatments (usually in the order late IPSP, baclofen, and THIP). Note that only 4 of the 5 neurons were exposed to THIP. The conductance activated by GTP $\gamma \mathrm{S}$ was estimated as described in the text. For the 3 subsequent conditions, this same estimate is displayed as the open portion of the bar graph, and the conductance added by each treatment is shown as the cross-hatched portion of the graph. The estimates of control values for the responses to baclofen, the late IPSP and THIP are displayed here for ease of comparison, and comprise the following cells: baclofen, results from all neurons exposed to 100 or 500 $\mu \mathrm{M}$ baclofen; late IPSP, data from all neurons subject to mossy fiber stimulation sufficient to elicit EPSP slopes of approximately $40 \mathrm{mV}$ / msec, as described in the text; THIP, all neurons exposed to $20 \mu \mathrm{M}$ THIP as in Figure 5.

toxin was unavailable to certain classes of cells (e.g., glia) or other types of neurons than pyramidal neurons.

Periussis toxin may have affected the late IPSP by acting upon a presynaptic site, and indeed calcium influx (Holz et al., 1986a; Dolphin and Scott, 1987) and transmitter release (Holz et al., 1986b) are reduced by baclofen through a pertussis toxin-sensitive G-protein in dorsal root ganglion neurons. However, a blockade of such an effect in presynaptic neurons should produce an increase, not a decrease, in the late IPSP. Alternatively, an undefined pertussis-sensitive mechanism might operate selectively upon presynaptic interneurons in the circuit that generates the late IPSP but not upon interneurons generating the early IPSP. However, these presynaptic mechanisms cannot account for the blockade of late IPSP and baclofen responses that followed injection of GTP $\gamma \mathrm{S}$ directly into the impaled postsynaptic neurons. Therefore, these effects of the toxin are better ascribed to effects upon pertussis toxin-sensitive G-proteins within the postsynaptic neurons.

\section{Type of G-protein responsible for the late IPSP}

Pertussis toxin does not affect $\mathrm{G}_{\mathrm{s}}$ that stimulates adenylyl cyclase (Birnbaumer et al., 1987; Gilman, 1987). This fact, together with the observation that the late IPSP is not affected by perfusion of forskolin (Hablitz and Thalmann, 1987) under conditions that elevate cyclic AMP several fold in hippocampal slices (Daly et al., 1982; Etgen and Browning, 1983; Fredholm et al., 1983) means that (1) the transmitter must not cause the late IPSP by acting through a $\mathrm{G}_{\mathrm{s}}$ adenylyl cyclase cascade nor 
(2) must the transmitter cause the late IPSP by a $G_{s}$ that might be coupled directly to a potassium conductance (see Yatani et al., $1987 \mathrm{c}$, for such an effect upon calcium channels). The abovementioned forskolin experiment (Hablitz and Thalmann, 1987) and similar experiments in CA1 neurons (Newberry and Nicoll, 1984) also appear to rule out a role for the inhibition of adenylyl cyclase through the pertussis toxin substrate $G_{i}$. Thus, the late IPSP conductance must depend upon a G-protein that is linked to potassium channels by some other means than through adenylyl cyclase.

The available data also do not favor the production of the late IPSP by a $G_{p}$, defined as a $G$-protein that stimulates a phospholipase C-diacylglycerol-protein kinase $\mathrm{C}$ cascade. Diacylglycerol agonists such as phorbol esters do not mimic the late IPSP but rather produce a depolarizing decrease in conductance (Baraban et al., 1985). Note, however, that since phorbol esters have been reported to decrease the late IPSP (Baraban et al., 1985), they therefore may be able to modulate some element of the receptor G-protein channel complex that mediates the late IPSP. Therefore, these data do not favor the control of the late IPSP by $G_{s}, G_{i}$, or $G_{p}$ as defined above, but they are consistent with the involvement of 2 other pertussis toxin substrates. The first is $\mathrm{G}_{\mathrm{o}}$, which is abundant in brain (Sternweis and Robishaw, 1984) and is possibly linked to calcium (Hescheler et al., 1987) and other channels, and the second is $G_{k}$, so named because it potently activates potassium channels in heart (Yatani et al., 1987a) and pituitary cells (Codina et al., 1987a).

\section{GTPrS activated a conductance similar to those it blocked}

Consistent with the expectation that GTP $\gamma S$ should activate G-proteins, GTP $\gamma$ S initiated a conductance that was similar to those it blocked in several respects. First, the reversal potential estimated for the GTP $\gamma \mathrm{S}$-activated conductance was virtually identical to that of the response to baclofen and the late IPSP. Second, the GTP $\gamma \mathrm{S}$-activated conductance was also similar to that associated with baclofen (Gahwiler and Brown, 1985) and the late IPSP (Hablitz and Thalmann, 1987) in that it gave no indication of outward rectification: It was robust at negative membrane potentials and, at least within the narrow limits tested $(-95$ to $-75 \mathrm{mV})$, did not increase with more positive membrane potentials. Third, as shown for the response to baclofen (Newberry and Nicoll, 1985; Andrade et al., 1986) and the late IPSP (Newberry and Nicoll, 1984), the GTP $\gamma$ S conductance could be activated in the face of increased cyclic AMP, in this case from the expected stimulation of adenylyl cyclase by GTP $\gamma$. Finally, the amplitude of the GTP $\gamma$-activated conductance was indistinguishable from that elicited by high concentrations of baclofen and was within three-quarters of that associated with maximal late IPSPs.

The amplitude of the potassium conductance associated with the late IPSP may correspond even more closely to the other 2 conductances when allowance is made for the contamination of the early portions of the maximal late IPSP by another response. The contaminating response is at least in part a depolarizing conductance that is augmented by pentobarbital and blocked by picrotoxin, an antagonist of $\mathrm{GABA}_{\mathrm{A}}$ action (Thalmann, 1988). A similar depolarizing synaptic response has been previously reported when $\mathrm{GABA}_{\mathrm{A}}$ responses were augmented by pentobarbital (Thalmann et al., 1981; Alger and Nicoll, 1982) or when synaptic responses were augmented by 4-aminopyridine (Avoli and Perreault, 1987).
The above data indicate, therefore, that GTP $\gamma \mathrm{S}$ activates a similar or perhaps identical conductance to that activated by baclofen and the transmitter of the late IPSP. Further, the blockade of the latter 2 conductances by GTP $\gamma \mathrm{S}$ can be seen as the activation of common elements of 3 conductance mechanisms by GTP $\gamma \mathrm{S}$, so that they are not available for further activation by agonists. Such common elements need not be the receptors since the injected GTP $\gamma$ S bypasses the cell-surface receptors to activate G-proteins directly. More likely, the putative common elements are the potassium channels, as proposed by Andrade et al. (1986), or elements of the intracellular signaling system such as the G-proteins themselves. In this light, it is noteworthy that GTP $\gamma$ S, which should activate all of the G-protein-coupled potassium conductances in these neurons, in fact initiated a conductance that was no larger than that associated with maximal responses to baclofen or the late IPSP. It is important to recognize that one possible explanation for this observation is that one or more kinds of transmitter receptors may have access to all of the G-protein potassium channel linkages in the neuron.

$G$-protein coupling between transmitter receptor and late IPSP potassium conductance

The properties of the late IPSP that were disclosed here easily fit the prevailing model for the G-protein control of potassium channels and other effectors, namely, that the G-proteins functionally link the transmitter receptors to these effectors (Rodbell, 1980; Birnbaumer et al., 1987; Gilman, 1987). The available data from other systems indicate that pertussis toxin functionally decouples transmitter receptors from their associated G-proteins, that is, the toxin primarily effects the interaction between receptor and $G$-protein rather than the interaction between G-protein and the effector (e.g., Cote et al., 1986; Birnbaumer et al., 1987). Such a decoupling of the receptors responsible for the late IPSP or baclofen conductances would easily account for the ability of the toxin to profoundly reduce these 2 agonist-gated conductances. The link between $\mathrm{G}$-protein and channel would, in turn, account for the ability of GTP $\gamma$ S to activate a conductance similar to that of the late IPSP or baclofen response and at the same time almost completely occlude those conductances.

Not only are the data of the present study easily accounted for by such a general $G$-protein linkage, but the coupling between a $\mathrm{G}$-protein and channel may be relatively direct since evidence has not been forthcoming for additional elements interposed in series between G-protéin and channel. For example, cyclic AMP is probably not such an element in this system, nor in other agonist-gated potassium conductances that depend upon pertussis toxin-sensitive G-proteins (Andrade et al., 1986; Codina et al., 1987a, b; Trussell and Jackson, 1987; Yatani et al., 1987a, b). Nor is the phospholipase C-stimulated cascade likely to be intercalated in this way. The diacylglycerol agonists, as already mentioned, do not mimic the late IPSP (Baraban et al., 1985), and the primary variables affected by inositol phospholipids, calcium and calcium channcls (Bcrridge, 1987), sccm not to play an intracellular postsynaptic role either in the late IPSP (Knowles et al., 1984; Newberry and Nicoll, 1984; Thalmann, 1984; Hablitz and Thalmann, 1987) or in the response to baclofen (Andrade et al., 1986).

Finally, at least for potassium channels gated by muscarine in atrial cells and by somatostatin in a pituitary cell line, no readily soluble proteins other than G-proteins seem to be required for the intracellular signaling between receptor and chan- 
nel: Agonist responses persist for many minutes in isolated membrane patches, provided only that the appropriate concentration of GTP is maintained to allow receptors to activate the $\mathrm{K}^{+}$channel regulatory $\mathrm{G}$-protein $\left(\mathrm{G}_{\mathrm{k}}\right)$ (Codina et al., 1987a, b; Yatani et al., 1987a, b).

\section{G-protein coupling: latency to activation}

With respect to the directness of the transmitter-channel signaling system for the late IPSP, it is of interest that the onset of the underlying current can occur within $25 \mathrm{msec}$ following the mossy fiber stimulus (Hablitz and Thalmann, 1987). This latency would not only seem to place some limits upon the complexity of the linkage, but would also indicate that the proposed transmitter receptor-G-protein-potassium channel system can operate somewhat more rapidly than previously demonstrated (see Hill-Smith and Purves, 1978; Osterrieder et al., 1980; Nargeot et al., 1982).

\section{$G$-protein coupling: relation to identity of late IPSP transmitter}

These experiments mean that the transmitter(s) of the late IPSP must be member(s) of the class of hippocampal transmitter candidates that also appear to act upon potassium channels via a pertussis toxin-sensitive G-protein (e.g., GABA and GABA and 5-HT: Andrade et al., 1986; adenosine: Trussel and Jackson, 1987; and norepinephrine: Aghajanian and Wang, 1986). The blockade by pertussis toxin and GTP $\gamma \mathrm{S}$ of both the late IPSP and the response to baclofen is consistent with GABA, via its $\mathrm{GABA}_{\mathrm{B}}$ receptor, acting as the transmitter for the late IPSP but does not, in itself, rule out other members of this class.

\section{References}

Adams, P. R., and D. A. Brown (1975) Actions of $\gamma$-aminobutyric acid on sympathetic ganglion cells. J. Physiol. (Lond.) 250: 85-120.

Aghajanian, G. K., and Y.-Y. Wang (1986) Pertussis toxin blocks the outward currents evoked by opiate and $\alpha_{2}$-agonists in locus coeruleus neurons. Brain Res. 371: 390-394.

Alger, B. E. (1984) Characteristics of a slow hyperpolarizing synaptic potential in rat hippocampal pyramidal cells in vitro. J. Neurophysiol. 52: 892-910.

Alger, B. E., and R. A. Nicoll (1982) Pharmacological evidence for two kinds of GABA receptor on rat hippocampal pyramidal cells studied in vitro. J. Physiol. (Lond.) 328: 125-141.

Andersen, P., J. C. Eccles, and Y. Loyning (1964) Pathway of postsynaptic inhibition in the hippocampus. J. Neurophysiol. 27: 608619.

Andrade, R., R. C. Malenka, and R. A. Nicoll (1986) A G protein couples serotonin and $\mathrm{GABA}_{\mathrm{B}}$ receptors to the same channels in hippocampus. Science 234: 1261-1265.

Avoli, M., and P. Perreault (1987) A GABAergic depolarization potential in the hippocampus disclosed by the convulsant 4-aminopyridine. Brain Res. 400: 191-195.

Baraban, J. M., S. H. Snyder, and B. E. Alger (1985) Protein kinase $C$ regulates ionic conductance in hippocampal pyramidal neurons: Electrophysiological effects of phorbol esters. Proc. Natl. Acad. Sci. USA 82: 2538-2542.

Berridge, M. J. (1987) Inositol trisphosphate and diacylglycerol: Two interacting second messengers. Annu. Rev. Biochem. 56: 159-193.

Birnbaumer, L., J. Codina, R. Mattera, A. Yatani, N. Scherer, M. J. Toro, and A. M. Brown (1987) Signal transduction by G-proteins. Kidney Int. 32(Suppl. 23): S14-S17.

Bowery, N. G., D. R. Hill, and A. L. Hudson (1983) Characteristics of the $\mathrm{GABA}_{\mathrm{B}}$ receptor binding sites on rat whole brain synaptic membranes. Br. J. Pharmacol. 78: 191-206.

Codina, J., D. Grenet, A. Yatani, L. Birnbaumer, and A. M. Brown (1987a) Hormonal regulation of pituitary $\mathrm{GH}_{3}$ cell $\mathrm{K}^{+}$channels by $\mathrm{G}_{\mathrm{k}}$ is mediated by its alpha subunits. FEBS Lett. 216: 104-106.
Codina, J., A. Yatani, D. Grenet, A. M. Brown, and L. Birnbaumer (1987b) The $\alpha$ subunit of the GTP binding protein $\mathrm{G}_{\mathrm{k}}$ opens atrial potassium channels. Science $236: 442-445$.

Cote, T. E., F. A. Frey, and R. D. Sekura (1986) Resolution of agonists and GPP(NH)P-mediated adenylate cyclase inhibition with pertussis toxin. In Pertussis Toxin, R. D. Sekura, J. Moss, and M. Vaughan, eds., pp. 129-149, Academic, New York.

Daly, J. W., W. Padgett, and K. B. Seamon (1982) Activation of cyclic AMP-generating systems in brain membranes and slices by the diterpene forskolin: Augmentation of receptor-mediated responses. J. Neurochem. 38: 532-544.

Dolphin, A. C., and R. H. Scott (1987) Calcium channel currents and their inhibition by $(-)$-baclofen in rat sensory neurones: Modulation by guanine nucleotides. J. Physiol. (Lond.) 386: 1-17.

Dutar, P., and R. A. Nicoll (1988) A physiological role for $\mathrm{GABA}_{\mathrm{B}}$ receptors in the central nervous system. Nature 332: 156-158.

Etgen, A. M., and E. T. Browning (1983) Activators of cyclic adenosine $3^{\prime}: 5^{\prime}$-monophosphate accumulation in rat hippocampal slices: Action of vasoactive intestinal peptide (VIP). J. Neurosci. 3: 2487-2493.

Falch, E., and P. Krogsgaard-Larsen (1982) The binding of the GABA agonist $\left({ }^{3} \mathrm{H}\right)$-THIP to rat brain synaptic membranes. J. Neurochem. 38: 1123-1129.

Fredholm, B. B., B. Jonzon, and K. Lindstrom (1983) Adenosine receptor mediated increases and decreases in cyclic AMP in hippocampal slices treated with forskolin. Acta Physiol. Scand. 117: 461463.

Gahwiler, B. H., and D. A. Brown (1985) GABA- $\beta$-receptor-activated $\mathrm{K}^{+}$current in voltage-clamped CA3 pyramidal cells in hippocampal cultures. Proc. Natl. Acad. Sci. USA 82: 1558-1562.

Gilman, A. G. (1987) G-proteins: Transducers of receptor-generated signals. Annu. Rev. Biochem. 56: 615-649.

Haas, H. L., B. Schaerer, and M. Vosmansky (1979) A simple perfusion chamber for the study of nervous tissue slices in vitro. J. Neurosci. Methods 1: 323-325.

Hablitz, J. J., and R. H. Thalmann (1987) Conductance changes underlying a late synaptic hyperpolarization in hippocampal CA3 neurons. J. Neurophysiol. 58: 160-179.

Hasuo, H., and J. P. Gallagher (1988) Comparison of antagonism by phaclofen of baclofen induced hyperpolarizations and synaptically mediated late hyperpolarizing potentials recorded intracellularly from rat dorsolateral septal neurons. Neurosci. Lett. 86: 77-81.

Hescheler, J., W. Rosenthal, W. Trautwein, and G. Schultz (1987) The GTP-binding protein, $\mathrm{G}_{0}$, regulates neuronal calcium channels. $\mathrm{Na}-$ ture $325: 445-447$.

Hill-Smith, I., and R. D. Purves (1978) Synaptic delay in the heart. An iontophoretic study. J. Physiol. (Lond.) 279: 31-54.

Holz, G. G., K. Dunlap, and R. M. Kream (1986b) Pertussis toxinsensitive GTP-binding proteins couple $\alpha-2$ and GABA-B receptors to inhibition of neurosecretion in dorsal root ganglion cells. Soc. Neurosci. Abstr. 12: 1195.

Holz, G. G., S. G. Rane, and K. Dunlap (1986a) GTP-binding proteins mediate transmitter inhibition of voltage-dependent calcium channels. Nature 319: 670-672.

Inoue, M., T. Matsuo, and N. Ogata (1985) Baclofen activates voltagedependent and 4-aminopyridine-sensitive $\mathrm{K}^{+}$conductance in guinea pig hippocampal pyramidal cells maintained in vitro. $\mathrm{Br}$. J. Pharmacol. 84: 833-841.

Kehl, S. J., and H. McLennan (1985) An electrophysiological characterization of inhibitions and postsynaptic potentials in rat hippocampal CA3 neurons in vitro. Exp. Brain Res. 60: 299-308.

Knowles, W. D., J. H. Schneiderman, H. V. Wheal, C. E. Stafstrom, and P. A. Schwartzkroin (1984) Hyperpolarizing potentials in guinea pig hippocampal CA3 neurons. Cell Mol. Neurobiol. 4: 207-230.

Lancaster, B., and P. R. Adams (1986) Calcium-dependent current generating the afterhyperpolarization of hippocampal neurons. $\mathrm{J}$. Neurophysiol. 55: 1268-1282.

Nargeot, J., H. A. Lester, N. J. M. Birdsall, J. Stockton, N. H. Wassermann, and B. F. Erlanger (1982) Studies of binding and of conductance relaxations in frog heart. J. Gen. Physiol. 79: 657-678.

Newberry, N. R., and R. A. Nicoll (1984) A bicuculline-resistant inhibitory post-synaptic potential in rat hippocampal pyramidal cells in vitro. J. Physiol. (Lond.) 348: 239-254.

Newberry, N. R., and R. A. Nicoll (1985) Comparison of the action of baclofen with $\gamma$-aminobutyric acid on rat hippocampal pyramidal cells in vitro. J. Physiol. (Lond.) 360: 161-185. 
Nicoll, R. A., and B. E. Alger (1981) Synaptic excitation may activatc a calcium-dependent potassium conductance in hippocampal pyramidal cells. Science 212: 957-958.

Osterrieder, W., A. Noma, and W. Trautwein (1980) On the kinetics of the potassium channel activated by acetylcholine in the S-A node of the rabbit heart. Pfluegers Arch. 386: 101-109.

Ribeiro-Neto, F., L. Birnbaumer, and J. B. Field (1987) ADP-ribosylation of G-proteins by pertussis toxin and cholera toxin in isolated membranes. Different requirements for and effects of guanine nucleotides and $\mathrm{Mg}^{2+}$. Mol. Endocrinol. 1: 472-481.

Rodbell, M. (1980) The role of hormone receptors and GTP-regulatory proteins in membrane transduction. Nature 284: 17-22.

Sternweis, P. D., and J. D. Robishaw (1984) Isolation of two proteins with high affinity for guanine nucleotides from membranes of bovine brain. J. Biol. Chem. 259: 13806-13813.

Tamura, M., K. Nogimori, S. Murai, M. Yajima, K. Ito, T. Katada, M. $\mathrm{Ui}$, and S. Ishii (1982) Subunit structure of islet-activating protein, pertussis toxin. In conformity with the A-B model. Biochemistry 21 : $5516-5522$.

Thalmann, R. H. (1984) Reversal properties of an EGTA-resistant late hyperpolarization that follows synaptic stimulation of hippocampal neurons. Neurosci. Lett. 46: 103-108.

Thalmann, R. H. (1987) Pertussis toxin blocks a late inhibitory postsynaptic potential in hippocampal CA3 neurons. Neurosci. Lett. 82: $41-46$.

Thalmann, R. H. (1988) Blockade of a late inhibitory postsynaptic potential in hippocampal CA3 neurons in vitro reveals a late depolarizing potential that is augmented by pentobarbital. Neurosci. Lett. (in press).
Thalmann, R. H., and G. F. Ayala (1982) A late increase in potassium conductance follows synaptic stimulation of granule neurons of the dentate gyrus. Neurosci. Lett. 29: 243-248.

Thalmann, R. H., and D. Grenet (1987) A GTP-binding protein other than Gs may mediate a late synaptic potassium $(\mathrm{K})$ conductance in hippocampal neurons. J. Neurochem. Abstr. 48: S77.

Thalmann, R. H., and N. Hershkowitz (1985) Some factors that influence the decrement in the response to GABA during its continuous iontophoretic application to hippocampal neurons. Brain Res. 342: 219-233.

Thalmann, R. H., E. J. Peck, and G. F. Ayala (1981) Biphasic response of hippocampal pyramidal neurons to GABA. Neurosci. Lett. 21: 319-324.

Trussell, L. O., and M. B. Jackson (1987) Dependence of an adenosineactivated potassium current on a GTP-binding protein in mammalian central neurons. J. Neurosci. 7: 3306-3316.

Yatani, A., J. Codina, A. M. Brown, and L. Birnbaumer (1987a) Direct activation of mammalian atrial muscarinic potassium channels by GTP regulatory protein $G_{k}$. Science 235: 207-211.

Yatani, A., J. Codina, R. D. Sekura, L. Birnbaumer, and A. M. Brown (1987b) Reconstitution of somatostatin and muscarinic receptormediated stimulation of $\mathrm{K}^{+}$channels by isolated $\mathrm{G}_{\mathrm{k}}$ protein in clonal rat anterior pituitary cell membranes. Mol. Endocrinol. 1: 283-289. Yatani, A., J. Codina, Y. Imoto, J. P. Reeves, L. Birnbaumer, and A. M. Brown (1987c) A G-protein directly regulates mammalian cardiac calcium channels. Science 238: 1288-1292. 